Article

\title{
Cardiopulmonary Activity Monitoring Using Millimeter Wave Radars
}

\author{
Elías Antolinos 1,*iD, Federico García-Rial ${ }^{1}$, Clara Hernández ${ }^{1}$, Daniel Montesano ${ }^{1}$, \\ Juan I. Godino-Llorente ${ }^{2}$ and Jesús Grajal ${ }^{1}$ \\ 1 Information Processing and Telecomunications Center, Universidad Politécnica de Madrid, \\ E.T.S.I Telecomunicación, Av. Complutense 30, 28040 Madrid, Spain; fa.garcia@upm.es (F.G.-R.); \\ c.hernandez@upm.es (C.H.); daniel.montesano.martinez@alumnos.upm.es (D.M.); \\ jesus.grajal@upm.es (J.G.) \\ 2 Department of Audiovisual and Communications Engineering, Universidad Politécnica de Madrid, \\ Nicola Tesla, s/n, 28031 Madrid, Spain; ignacio.godino@upm.es \\ * Correspondence: elias.antolinos@upm.es
}

Received: 22 June 2020; Accepted: 12 July 2020; Published: 15 July 2020

\begin{abstract}
Current cardiopulmonary activity monitoring is based on contact devices which cannot be used in extreme cases such as premature infants, burnt victims or rescue operations. In order to overcome these limitations, the use of radar technologies emerges as an alternative. This paper aims to enhance the comprehension that non-contact technologies, in particular radar techniques, offer as a monitoring tool. For this purpose, a modified low cost commercial $122 \mathrm{GHz}$ frequency-modulated continuous-wave (FMCW) radar is used to better fit the current application domain. The radar signals obtained are processed using a classic linear filtering algorithm aiming to separate the breathing from the heartbeat component while preserving signals integrity. In a standoff configuration and with different subject orientations, results show that the signal obtained with the radar can be used to extract not only the respiratory and heartbeat rates, but also the heart rate variability (HRV) sequence. Moreover, results evidence the coupling between breathing and heartbeat, also showing that the HRV sequence obtained can identify the respiratory sinus arrhythmia (RSA) effect. Finally, the radar is tested in a simultaneous multi-target scenario, demonstrating its monitoring capabilities in more complex situations. Nevertheless, there are some challenges left to use the system in a real-life monitoring environments, such as the removal of random body movements.
\end{abstract}

Keywords: cardiopulmonary activity; non-contact monitoring; vital sign monitoring; FMCW radar; HRV; signal separation; RSA; heartbeat; multi-target vital sign detection

\section{Introduction}

Noncontact monitoring of cardiopulmonary activity has gained attraction in the past decade since it is a promising solution to overcome difficulties during sleep monitoring, patients in a burn unit, post-surgery monitoring, newborn infants, or in rescue working, because it makes possible to control and monitor people remotely, without a wired system [1-3]. It results in a more comfortable situation for the patient, creating better conditions for more accurate diagnoses. Moreover, there is a growing percentage of population suffering from cardiovascular diseases [4] and the demographical changes in the last decades point towards an aging population which implies a large increase in medical costs. Additionally, home monitoring and telehealth, which are enabled by noncontact monitoring, allow early detection of worsening conditions which would decrease these costs by reducing the number of hospital admissions and bed days of care [5-7].

Cardiopulmonary activity monitoring is based on measuring one or more physiological effects of mechanical or electrical nature occurring in the heart, the lung or both. The most used 
cardiorespiratory monitoring techniques require contact or invasive interactions with the patient such as the electrocardiogram (ECG) or the photoplethysmogram (PPG), which are the gold standard techniques for heart monitoring. The ECG is a measure of the electrical changes of the heart over time, as a result of the muscle cells depolarization during each cardiac cycle [8]. On the other hand, the PPG is a non-invasive technique for measuring changes in blood flow through tissues by the emission of infrared light [9]. However, the use of contact sensors is neither possible nor desirable in many situations. With the aim of overcoming this limitation, some noncontact-based instruments have been developed such as the ballistocardiograph (BCG) [10], the seismocardiograph (SCG) [11], video-based motion analysis methods [12], laser-based methods [13], thermal methods [14] or radar monitoring, which is the main issue in this paper. All of them are based on the body surface displacement caused by organ motion and deformation and fluid displacement produced by breathing and heartbeat as explained in [15]. The main characteristics of these noncontact monitoring techniques are listed in Table 1. Nevertheless, they are not normally used in clinical environments due to lack of reliability, accuracy and automatization [1]. For that reason, the aim of this work is to enhance the comprehension that radar technologies offer as a monitoring and diagnosis tool.

Table 1. Main characteristics and limitations of non-contact devices for cardiorespiratory monitoring.

\begin{tabular}{|c|c|c|}
\hline $\begin{array}{l}\text { Non-Contact } \\
\text { Devices }\end{array}$ & Working Principle & Limitations \\
\hline Laser-based & $\begin{array}{l}\text { Method that measures chest displacement } \\
\text { using light. }\end{array}$ & $\begin{array}{l}\text { - Only capable of monitoring one subject at a } \\
\text { time. } \\
\text { - } \quad \text { High cost. }\end{array}$ \\
\hline $\begin{array}{l}\text { Video motion } \\
\text { monitoring }\end{array}$ & $\begin{array}{l}\text { Method that films the displacement of the } \\
\text { body surface. }\end{array}$ & - Sensitive to illumination. \\
\hline Thermal-based & $\begin{array}{l}\text { Method that, measuring temperature changes, } \\
\text { allows a representation of the heartbeat } \\
\text { and breathing. }\end{array}$ & $\begin{array}{l}\text { - } \quad \text { Sensitive to ambient temperature. } \\
\text { - } \quad \text { High cost. }\end{array}$ \\
\hline Ballistocardiograph & $\begin{array}{l}\text { Method that obtains the heartbeat and } \\
\text { breathing due to repetitive movements of the } \\
\text { human body, occurring because of acceleration } \\
\text { of blood as it is ejected and moved in the } \\
\text { vessels during the cardiac cycle. }\end{array}$ & $\begin{array}{l}\text { - Artifacts due to patient motion. } \\
\text { - Complexity of the system: sensors and } \\
\text { accelerometers. } \\
\text { - It requires a direct mechanical coupling } \\
\text { with the subject. } \\
\text { Only capable of monitoring one subject at a } \\
\text { time. }\end{array}$ \\
\hline Seismocardiograph & $\begin{array}{l}\text { Method that measures the heartbeat and } \\
\text { breathing due to the vibrations of the chest wall. }\end{array}$ & $\begin{array}{l}\text { - Artifacts due to patient motion. } \\
\text { - High sensitivity owing to sensor location } \\
\text { and accelerometer axes orientation. } \\
\text { - It requires a direct mechanical coupling } \\
\text { with the subject. } \\
\text { Only capable of monitoring one subject at a } \\
\text { time. }\end{array}$ \\
\hline Radar-based & $\begin{array}{l}\text { Method that captures the chest displacement } \\
\text { due to the frequency shift (velocity measure) } \\
\text { or phase difference (distance measure), which } \\
\text { occurs when the target from which the radar } \\
\text { wave is reflected moves. }\end{array}$ & $\begin{array}{l}\text { - } \\
\text { - } \quad \text { Artifacts due to patient motion. }{ }^{1}\end{array}$ \\
\hline
\end{tabular}

${ }^{1}$ Radar-tracking algorithms could be used to mitigate artifacts due to patient motion.

Noncontact detection and monitoring of cardiopulmonary activity using radar technology is known since 1975 [16]. However, until the advances in the late 90's allowed integrating a radar into a single chip, which made this technology compact, lightweight, mass-produced and inexpensive [17], this technology was not actually considered as an option. During the last two decades, studies 
have highlighted the numerous advantages of this method for cardiopulmonary activity monitoring, which make it the ideal technology for home monitoring or telehealth: measurement from distances of the order of meters or even through-wall measurements are possible [18], accurate measurements independent of orientation or point of view [19], and unobtrusive measurements to the subject (no need of sedation or drugs, no need of standing still, and the subject can be fully clothed [20]), which means that regular daily activities can be performed while being measured. Table 2 lists different approaches carried out for vital sign monitoring using continuous-wave $(\mathrm{CW})$ and frequency modulated continuous-wave (FMCW) radars.

Table 2. Vital sign monitoring with radar techniques.

\begin{tabular}{|c|c|c|c|c|}
\hline $\begin{array}{c}\text { Radar } \\
\text { Technology }\end{array}$ & $\begin{array}{l}\text { Frequency } \\
\text { (GHz) }\end{array}$ & Reference Signal & Results & Additional Comments \\
\hline CW [21] & 1.892 & $\begin{array}{l}\text { Finger pulse } \\
\text { sensor }\end{array}$ & $\begin{array}{l}\text { Respiratory and } \\
\text { heart rate }\end{array}$ & - \\
\hline CW [22] & 2.4 & $\begin{array}{l}\text { ECG and } \\
\text { respiratory belt }\end{array}$ & HRV & Analysis of RSA effect \\
\hline CW [23] & 15 & $\begin{array}{l}\text { Contact pulse } \\
\text { sensor (wrist) }\end{array}$ & $\begin{array}{l}\text { Reconstructed pulse } \\
\text { waveform }\end{array}$ & $\begin{array}{l}\text { Best cardiac motion detection from the front } \\
\text { but better heart-rate accuracy from the back }\end{array}$ \\
\hline CW [24] & 24 & ECG & HRV & Thorough analysis of HRV extraction \\
\hline CW [25] & 24 & Sphygmogram & $\begin{array}{l}\text { Reconstructed pulse } \\
\text { waveform }\end{array}$ & $\begin{array}{l}\text { Correlation between radar output and } \\
\text { sphygmogram measuring carotid, vein and } \\
\text { ventricle pressure }\end{array}$ \\
\hline CW [26] & 24 & ECG (Heart rate) & Heart rate & $\begin{array}{l}\text { Best performance measuring from the back } \\
\text { of a sitting patient }\end{array}$ \\
\hline CW [27] & 24 & $\begin{array}{l}\text { ECG (Identifying } \\
\text { cardiac events) }\end{array}$ & $\begin{array}{l}\text { Respiratory and } \\
\text { heart rate }\end{array}$ & $\begin{array}{l}\text { Correlation between the radar output and } \\
\text { the overall cardiac volume conducted } \\
\text { through skin }\end{array}$ \\
\hline CW [28] & 228 & $\begin{array}{l}\text { ECG and } \\
\text { respiratory belt }\end{array}$ & $\begin{array}{l}\text { Respiratory and } \\
\text { heart rate }\end{array}$ & Measurements up to $50 \mathrm{~m}$ \\
\hline FMCW [29] & $24.05-24.25$ & $\begin{array}{l}\text { Piezoelectric finger } \\
\text { sensor }\end{array}$ & Heart rate & $\begin{array}{l}\text { Simultaneously heart rate detection of } \\
\text { multiple subjects }\end{array}$ \\
\hline FMCW [30] & $77-81$ & - & $\begin{array}{l}\text { Respiratory and } \\
\text { heart rate }\end{array}$ & $\begin{array}{l}\text { Simultaneously vital sign detection of } \\
\text { multiple subjects, uses MIMO }\end{array}$ \\
\hline FMCW [19] & $75-85$ & $\begin{array}{l}\text { Philips MP70: } \\
\text { ECG }+\mathrm{CO}_{2} \\
\text { changes }\end{array}$ & $\begin{array}{l}\text { Respiratory and } \\
\text { heart rate }\end{array}$ & - \\
\hline FMCW [31] & $118.5-125.5$ & $\begin{array}{l}\text { Respiratory belt } \\
\text { and pulsioximeter }\end{array}$ & $\begin{array}{l}\text { Respiratory and } \\
\text { heart rate }\end{array}$ & - \\
\hline $\begin{array}{l}\text { FMCW } \\
\text { [this work] }\end{array}$ & $114-130$ & ECG & $\begin{array}{c}\text { Reconstructed } \\
\text { breathing and } \\
\text { heartbeat waveforms, } \\
\text { HRV, and respiratory } \\
\text { and heart rate }\end{array}$ & $\begin{array}{l}\text { Simultaneously vital sign detection of } \\
\text { multiple subjects and analysis of coupling } \\
\text { between breathing and heartbeat }\end{array}$ \\
\hline
\end{tabular}

Therefore, the main approach of radar-based vital sign detection is the measure of the chest vibrations resulting from the mechanical effects of breathing and the cardiac cycle. These signals have been thoroughly analyzed in the literature, allowing a fair characterization of their waveform. The heartbeat signal has a fundamental frequency between $0.9 \mathrm{~Hz}$ and $3 \mathrm{~Hz}$ ( 54 to 180 beats/min), and an amplitude which is around $0.5 \mathrm{~mm}$ measured from the chest. On the other hand, the breathing signal has a fundamental frequency between 0.1 and $0.7 \mathrm{~Hz}$ ( 6 to 42 breaths $/ \mathrm{min}$ ), and an amplitude which is in the 4 and $12 \mathrm{~mm}$ interval measured from the chest [1]. In addition, it is important to highlight that the shape of the heartbeat waveform varies significantly depending on where it is measured, as was stated in [25]. Observing the results extracted in [25,32-34], it can be concluded that the heartbeat waveform extracted with the radar is highly correlated to the arterial pressure waveform. Being this pressure waveform widely used for monitoring and cardiac disease diagnosis [35-37].

Moreover, several diagnostic indicators can be extracted from this waveform, for instance, the heart rate variability (HRV). It is a widely used as a non-invasive tool to assess the autonomic 
nervous system (ANS) activity, being used as a biomarker of some disorders, such as sleep apnea, sudden cardiac death, diabetic neuropathy or stress [38-42]. The concept behind the HRV was firstly introduced by Stephen Hales in 1733 [43], when he noticed a variation in the arterial blood pressure and time length between beats during the respiration cycle of horses. However, it was not until 1847 when this phenomenon was documented by Carl Ludwig [44], stating an increase in the heart rate during inhalation and a decrease during exhalation. Nowadays, this fact is known as respiratory sinus arrhythmia (RSA), and it proves that a coupling between breathing and heartbeat exists. Figure 1 illustrates the heart rate variation due to the breathing process, where it can also be observed the ECG amplitude modulation due to the breathing [45]. Moreover, it shows how during inhalation the subject chest volume increases, reducing the distance between the radar setup and the region measured, which is represented with negative amplitude values. Additionally, the HRV and RSA provide diagnostic capabilities to identify respiratory disorders such as central sleep apnea, chronic obstructive pulmonary disease or asthma, and refine diagnostic procedures [20,46-48].

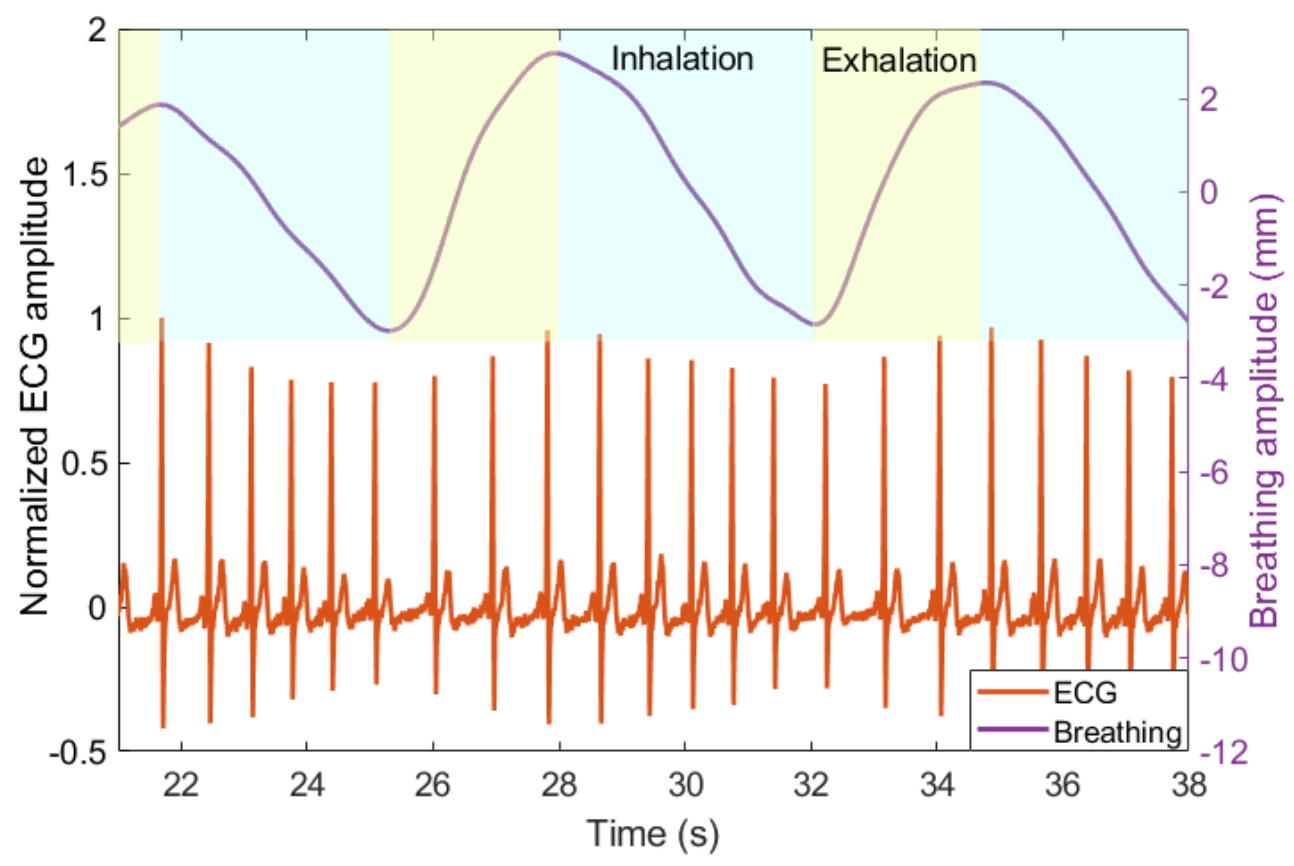

Figure 1. Breathing waveform extracted with the $122 \mathrm{GHz}$ radar setup compared with its ECG reference. The inhalation and exhalation processes are illustrated.

Thus, as previously enunciated, the main idea of this work is to carry out a comprehensive approach to point out the radar potential in the vital sign monitoring area. The principal objective is to be able to use the radar system as a monitoring tool. This goal has been addressed with breathing and heartbeat waveform separation, being able to identify characteristic events, and with the HRV extraction. Moreover, it has been illustrated the coupling between breathing and heartbeat, in terms of harmonic power and showing the RSA effect. Finally, the simultaneous monitoring of multiple subjects is presented, taking advantage of the FMCW technology.

To that end, a commercial radar module working at $122 \mathrm{GHz}$, within an ISM band [49], is used for monitoring cardiopulmonary activity, which is described in Section 2.2. The working frequency has not been chosen arbitrarily, its election is based on two main facts. On the one hand, the frequency of $122 \mathrm{GHz}$ belongs to an ISM band. On the other hand, increasing the working frequency enhances the measurement accuracy, since, at high frequencies, small displacements result in significant phase changes, as it is detailed in Section 2.1. Furthermore, the acquired signal is compared with a 3-lead ECG that is used as a reference. This comparison shows the correlation between the heart electrical response, measured with the ECG, and its mechanical response, measured with the radar. 
The rest of this paper is organized as follows. Section 2 explains the FMCW radar working principle, describes the radar module used and the signal processing scheme followed to separate the vital sign waveforms. Section 3 details three experiments carried out to show the potential of radar technologies in the frame of vital signal monitoring: firstly, a breathing and heartbeat waveform extraction in breathing and apnea conditions; secondly, an analysis of breathing and cardiac activity coupling, in particular the HRV and RSA effect at different body orientations; and lastly, a multi-target vital sign monitoring. Finally, the presented results are discussed in Section 4, and conclusions are drawn in Section 5.

\section{Materials and Methods}

\subsection{FMCW Radar Working Principle}

A frequency modulated signal is transmitted towards the chest or the back of subjects, lying or sitting. Chest displacements due to breathing and heartbeat are measured through the phase modulation present in the received signal, delivering a signal that contains the breathing and heartbeat effects. Both the instantaneous frequency of the transmitted and the received radar signals can be observed in Figure 2.

The analytical signal (the real signal is the real part of this analytic signal: $s_{\text {real }}(t)=\Re\left(s_{T x}(t)\right)=$ $\left.\cos \left(2 \pi f_{c} t+\pi \gamma t^{2}+\Phi\right)\right)$ transmitted by a FMCW radar takes the form [50]:

$$
s_{T x}(t)=\exp \left(j\left(2 \pi f_{c} t+\pi \gamma t^{2}+\Phi\right)\right)
$$

where $f_{c}$ is the central frequency, $\gamma=B / T$ is the chirp rate being $B$ the transmitted bandwidth and $T$ the repetition period, $\Phi$ is the initial phase (which in this section will be considered zero for simplicity), and $t$ is the so-called fast time for the interval, $t \in[-T / 2, T / 2]$.

Under the "stop and go assumption", which states that the target does not change its position during the time interval $T$, the received signal for a point scatterer at a range $R\left(\tau_{i}\right)$ (where $\tau$ is the so-called slow time (mathematically, the slow time can be expressed as $\tau_{i}=i \cdot T$, with $i \in \mathbb{Z}$, so it is a sampled version of the fast time $t$ ) and index $i$ refers to each transmit period, $T$ ) for each transmitted chirp is:

$$
s_{R x}\left(t, \tau_{i}\right) \propto \sqrt{\sigma} s_{T x}\left(t-\frac{2 R\left(\tau_{i}\right)}{c}\right)
$$

where $\frac{2 R\left(\tau_{i}\right)}{c}$ is the round-trip delay, and $\sigma$ is the radar-cross section (RCS).

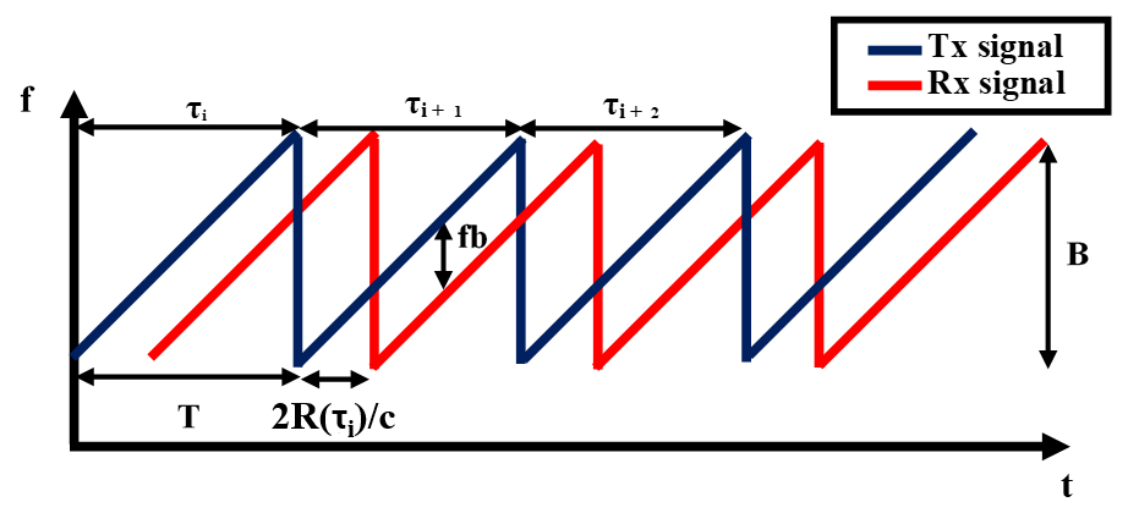

Figure 2. Working principle of FMCW radars. $B$ stands for the transmitted bandwidth, $T$ is the repetition period and $2 * R\left(\tau_{i}\right) / c$ is the round-trip delay, i.e., the time that the transmitted signal takes to be returned to the radar by a target at $R\left(\tau_{i}\right)$. 
After mixing the transmitted signal with the received one, the beat signal is obtained:

$$
\begin{aligned}
s_{b}\left(t, \tau_{i}\right) & =s_{T x}(t) s_{R x}^{*}(t)= \\
& =\sqrt{\sigma} \exp \left(j\left(\frac{4 \pi \gamma R\left(\tau_{i}\right) t}{c}+\frac{4 \pi f_{c} R\left(\tau_{i}\right)}{c}-\frac{4 \pi \gamma R^{2}\left(\tau_{i}\right)}{c^{2}}\right)\right)= \\
& \left.=\sqrt{\sigma} \exp \left(j 2 \pi f_{b}\left(\tau_{i}\right) t+\phi\left(\tau_{i}\right)+\phi_{2}\left(\tau_{i}\right)\right)\right)
\end{aligned}
$$

The beat signal follows a sinusoidal waveform with a frequency known as beat frequency $f_{b}\left(\tau_{i}\right)$. Identifying terms in the previous equation, $f_{b}\left(\tau_{i}\right)=2 \gamma R\left(\tau_{i}\right) / c$, thus, the beat frequency is proportional to the target range [50]. On the other hand, the phase of the beat signal $s_{b}\left(t, \tau_{i}\right)$ is denoted as $\phi\left(\tau_{i}\right)=4 \pi f_{c} R\left(\tau_{i}\right) / c$, and contains information about the target range. Lastly, the term $\phi_{2}\left(\tau_{i}\right)=-4 \pi \gamma R^{2}\left(\tau_{i}\right) / c^{2}$ represents the residual video phase (RVP) [50], which is found to be negligible and can be ignored, since it is proportional to $1 / c^{2}$.

In view of the previous equations, $f_{b}\left(\tau_{i}\right)$ is used for target location, enabling person separation in multi-target measurements. This target separation is carried out with a digital filter bank, implemented with an FFT (Fast Fourier Transform). On the other hand, $\phi\left(\tau_{i}\right)$ is used to monitor the vibrations of the thorax produced by the breathing and heartbeat signals. A high central frequency is selected for the central frequency due to the system increases its sensitivity to small $\Delta R$ with this frequency: $\Delta \Phi \propto f_{c} \Delta R$.

\subsection{Radar Module}

The radar sensor is based on a $122 \mathrm{GHz}$ FMCW radar kit fabricated by Silicon Radar GmbH [51]. This product was chosen for its low cost, high flexibility, and its reduced overall size. The kit itself is based on a $8 \times 8 \mathrm{~mm}^{2}$ monolithic microwave integrated circuit (MMIC) transceiver with just $440 \mathrm{~mW}$ power consumption. Research related to this sensor and its previous versions may be found throughout the literature [52]. Its main characteristics are listed in Table 3. Within these characteristics, the most critical parameter for the intended application would be the radar's phase stability. This value is the maximum distance displacement produced by phase shifts in the received signal when the radar aims at a static target. Since the target is static, any registered phase shifts in the received signal must be due to atmospheric variations or the sensor's own phase noise. Therefore, this parameter can be interpreted as a measured limit for the phase-based measurements performed with the radar, where distance displacements with a corresponding phase shift lower than the sensor's phase stability cannot be accurately measured. The phase stability value in Table 3 has been measured by aiming the radar at a static metal plate during $0.8 \mathrm{~s}$ with $150 \mu \mathrm{s}$ chirps. Figure 3 shows a diagram of the set-up and the

\begin{tabular}{|c|c|}
\hline Characteristic & Value \\
\hline Center Frequency $(\mathrm{GHz})$ & 122 \\
\hline Output Power $(\mathrm{dBm})$ & -3 (without antennas) \\
\hline Bandwidth $(\mathrm{GHz})$ & $16(\max )$ \\
\hline Sweep Time & $12 \mu \mathrm{s}$ to $18 \mathrm{~ms}$ \\
\hline Beamwidth ${ }^{1}$ & $\begin{array}{c} \pm 30^{\circ} \\
\pm 4^{\circ} \text { (with the lens) }\end{array}$ \\
\hline Phase stability $(\mu \mathrm{m})(\max )$ & 1.91 \\
\hline
\end{tabular}
recorded distance histogram.

Table 3. Main characteristics of the radar module used.

${ }^{1}$ A dielectric lens has been fabricated to increase the flexibility of our set-up regarding the radar focusing, since the field of view $(\mathrm{FoV})$ of the radar in one dimension is: FoV $\approx$ Beamwidth $\cdot R$, where $\mathrm{R}$ is the target range. The use of the lens allows a narrower focusing. 


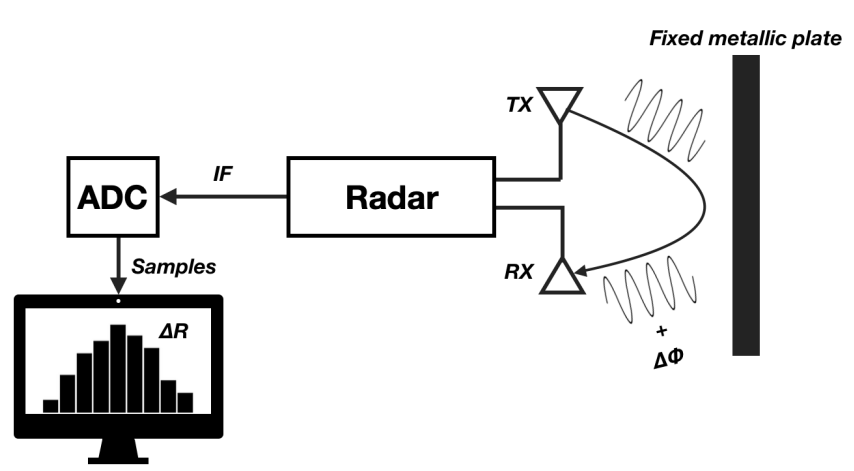

(a)

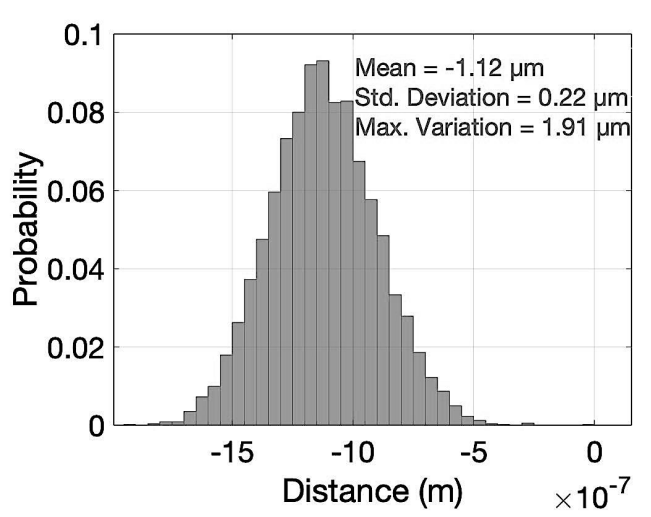

(b)

Figure 3. (a) Diagram of the measurement set-up for phase stability characterization, where the radar aims at a static metal plate. (b) Recorded histogram of the distance displacements due to phase shifts according to $\phi\left(\tau_{i}\right)=4 \pi f_{c} R\left(\tau_{i}\right) / c$.

The radar's summarized architecture, as well as a photograph, may be seen in Figure 4. Signal generation is achieved via a PLL (Phase-Locked Loop) synchronized with a voltage-controlled oscillator (VCO) at $60 \mathrm{GHz}$ and a phase-frequency detector (PFD) fed by a reference clock signal. After doubling the signal's frequency, transmission is performed by a dipole antenna. The reflected radiation is received by another such antenna, both placed directly on the chip [53] The received signal is mixed to produce I/Q signals which are conditioned in baseband and sampled with an external ADC, connected to a conventional PC for processing.

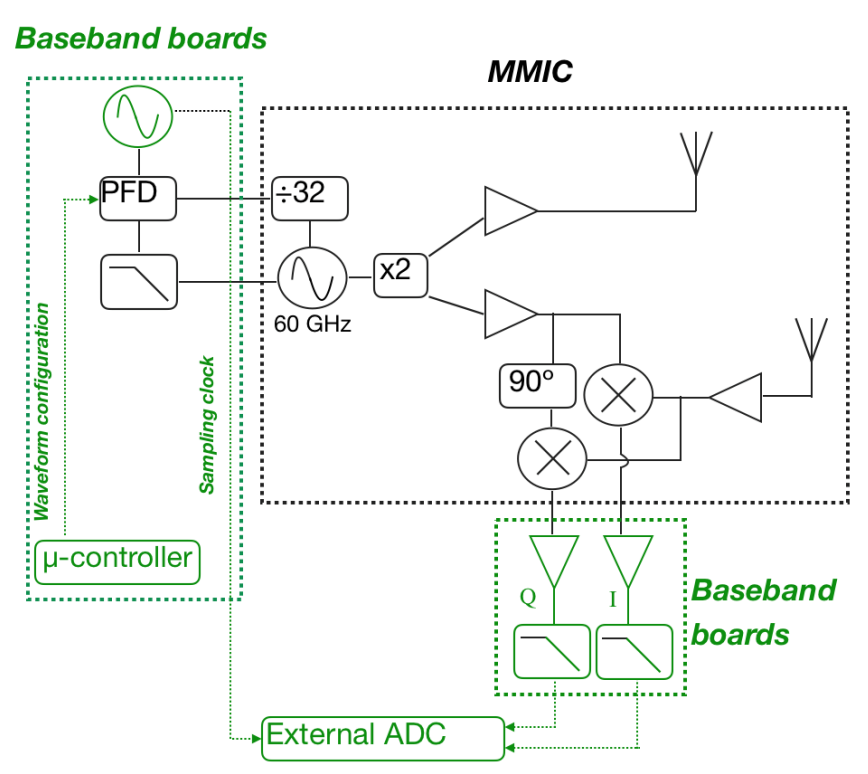

(a)

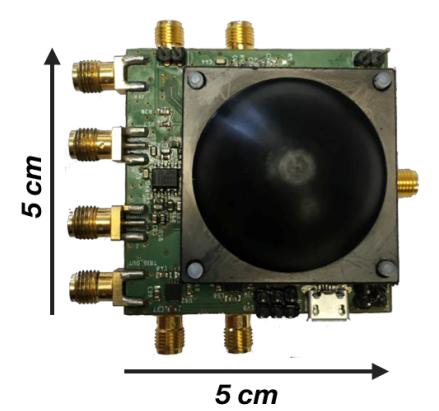

(b)

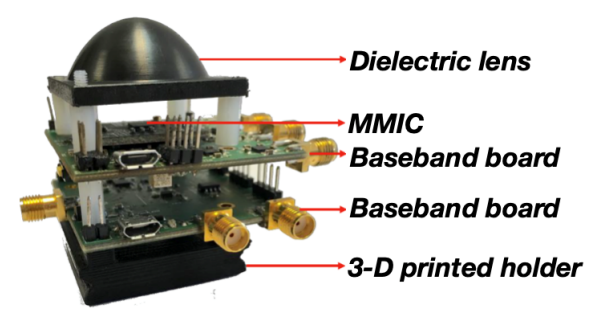

(c)

Figure 4. (a) Diagram of the radar's RF and baseband architecture. Items in green have been modified from the original commercial version. (b) Photograph of the sensor: top view. The connectors on the sides of the sensor are various I/Q, clock and trigger outputs. The microcontroller includes a USB connector to receive waveform configuration orders from a PC. (c) Photograph of the sensor: front view.

In order to better fit the desired application, the commercial version of the radar has been modified to the final architecture and description shown in Figure 4. The main modification has been 
the replacement of the commercial radar's microcontroller and baseband boards for custom-made PCBs, enabling its reduction in size to just $5 \times 5 \mathrm{~cm}^{2}$ and other improvements such as:

- Continuous FMCW operation: The commercial FMCW radar's transmission was limited to intervals managed by its microcontroller. These intervals included off-time between clusters of FMCW sweeps to allow for on-board signal processing and USB-to-PC data transmission as shown in Figure 5, which would hinder continuous cardiopulmonary measurements. Figure 5a shows both types of off-time originally preventing continuous transmission, while Figure $5 b$ confirms that data is composed of voltage ramps of the same amplitude as before the modifications and with faster sweeps. In the modified architecture the microcontroller has been removed so that all processing is offloaded to a PC, with a connected external ADC that continuously samples the I/Q signals.

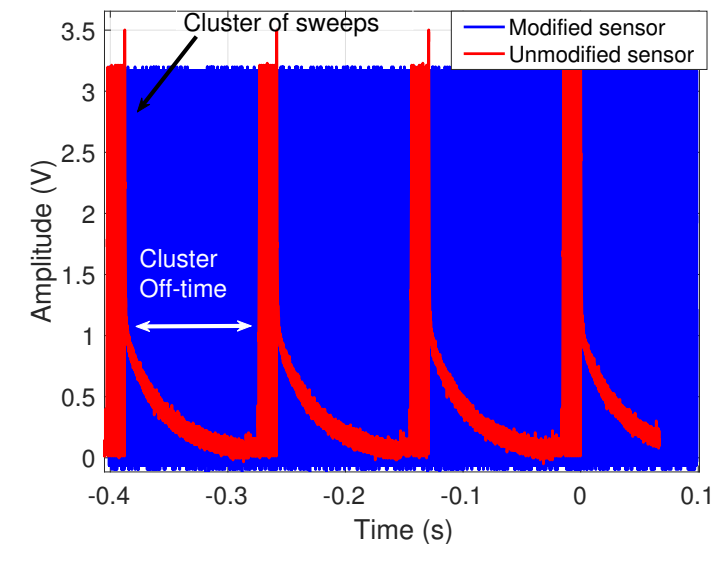

(a)

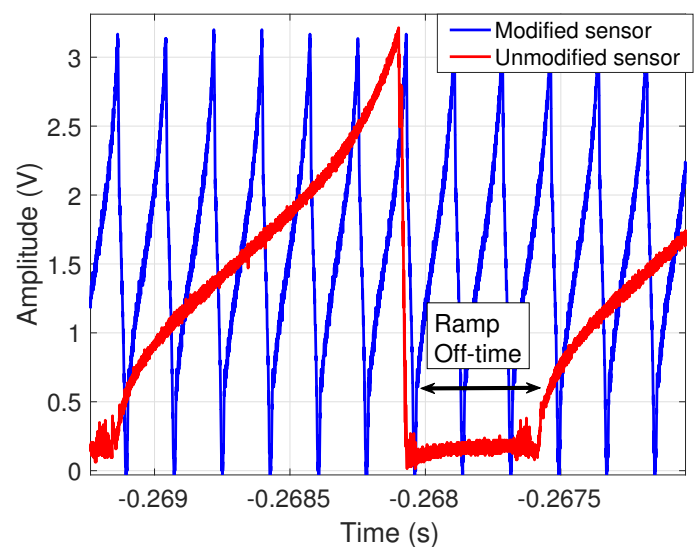

(b)

Figure 5. (a) Voltage ramps input into the MMIC's VCO for FMCW operation in the modified (in blue) and commercial sensor (in red). (b) Zoomed-in view.

- Cleaner signal reference: The reference oscillator used to feed the PFD has been replaced for another commercial component from the same manufacturer. Although slightly more expensive, the new reference provides less phase noise. This is an important feature in an upconversion architecture such as the one in Figure 4, because the phase noise will be increased in each multiplication stage, ultimately masking close low-power targets in the spectrum, as shown in Figure 6. Notice, in Figure 6b, the increase in dynamic range due to the reduction in phase noise of the new reference oscillator, which allows detection of the previously-masked target at around $1 \mathrm{~m}$ distance. This is specially useful in our desired application, since some of the returns from cardiopulmonary activity can present very low SNR. 


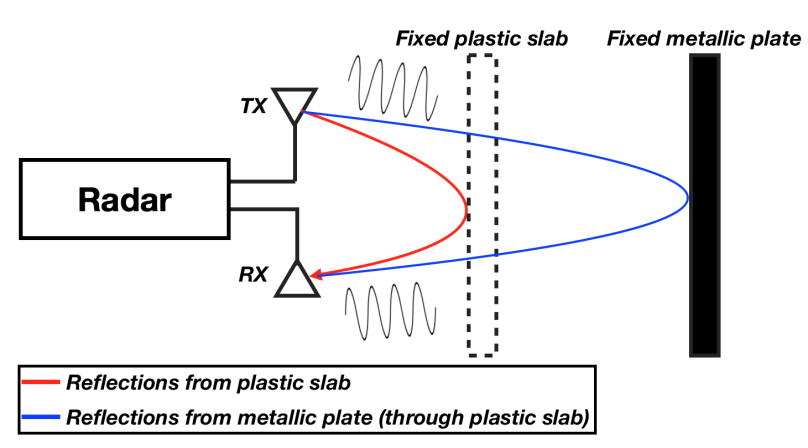

(a)

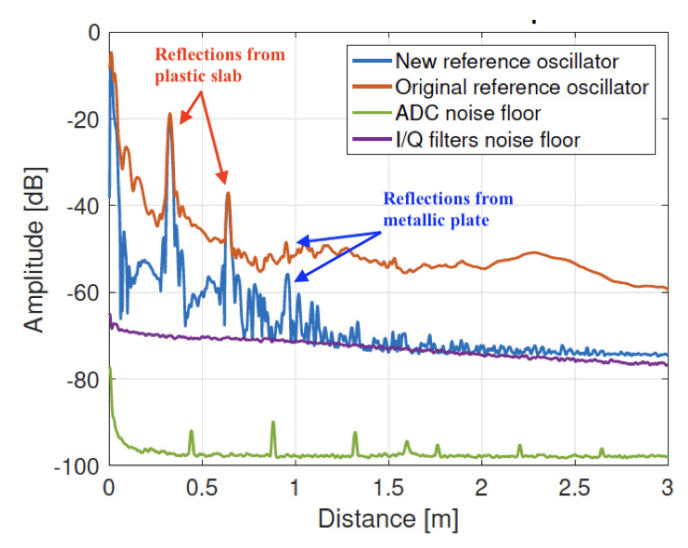

(b)

Figure 6. (a) Diagram of the measurement set-up for spectral noise characterization, where the radar aims at two targets in its line of sight: a penetrable plastic slab, and a metallic plate behind it. (b) Spectral comparison among different stages of the radar's architecture.

- Flexible waveform configurations: The replacement of the microcontroller allows for improved waveform configurations, including finer bandwidth and sweep time selections. This has enabled proper alignment of sweep flyback times, and triggering of the ADC's sampling using an end-of-ramp signal. Both improvements create better-synchronized waveform generation and sampling, producing less error in the cardiopulmonary measurements.

- Redesign of signal conditioning: Enabled by the removal of the commercial baseband board, the baseband signal conditioning has been modified for better adaptation to the desired application. This includes a redesign of the I/Q filters, which are now electronically-modified by the microcontroller, to adapt their cutoff frequency and gain to the specific needs of each measurement scenario.

- Cleaner power supply: In contrast to the commercial architecture, the power source of the noisy microcontroller (i.e., a USB port) can be made independent from the PLL's (which can be through voltage-regulated jack connector or dedicated pins). This provides a cleaner source for waveform generation, ultimately producing less spurs and/or harmonics in RF bands, which could be erroneously interpreted as useful cardiopulmonary information.

- Cost reduction: The removal of the commercial kit's baseband and microcontroller boards allows acquiring only the commercial MMIC. Including the fabrication of the custom-made PCBs, the overall cost of the modified sensor is approximately one third of the commercial radar's price, dropping down to $\sim 300 €$

In comparison to traditional mm-wave waveguide-based transceivers, the compactness, low cost, and low power consumption of this MMIC-based device make it an ideal sensor for cardiopulmonary activity monitoring. These properties would allow improvements to the usual fixed single sensor measurement set-up, such as portable sensors to be used on-field or even inexpensive installation of several sensors working together in a network $[6,7,54]$ (which could be useful for multi-view cardiopulmonary measurements).

\subsection{Signal Processing Scheme}

This section describes the pre-processing needed for the signal conditioning and the linear filtering algorithm used to extract the breathing and heartbeat waveforms. The signal processing scheme followed is illustrated in Figure 7, where the signal acquired with the radar requires a pre-processing step, followed by a classic filtering in the frequency domain to extract the desired signals. 


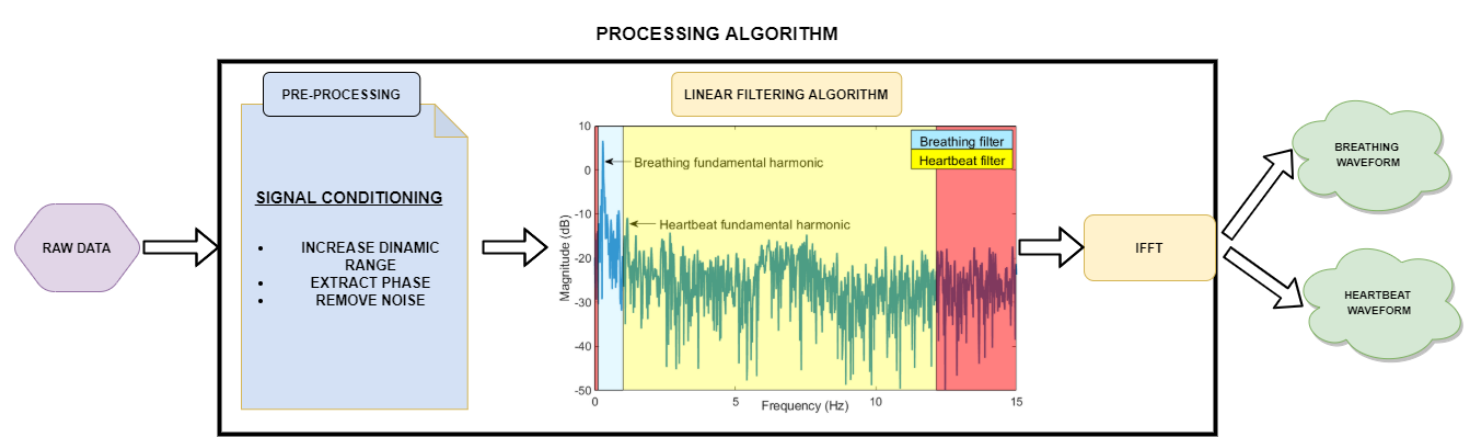

Figure 7. Block diagram showing the modules used to separate the breathing and heartbeat waveforms.

\subsubsection{Pre-Processing Module}

A previous conditioning of the signal is necessary before applying the processing algorithms, since the noise and random motion artifacts need to be mitigated to obtain accurate results. The pre-processing steps to accommodate the radar signal are described in Table 4. Steps 1-3 are used to prepare the signal and enhance the dynamic range. After that, an FFT is performed to identify the frequency range where the target's beat frequency is located. In step 5, the FFT is clipped in the predefined frequency range, with the aim of isolating the target from interfering objects in the radar's field of view. Then, for each chirp, the phase is computed at the beat frequency, which is selected by calculating the FFT maximum in the frequency range previously defined. After that FFT sub-sampling, the sampling frequency of the signal is in the range of $1-2 \mathrm{kHz}$.

Traditionally, the phase extraction is carried out directly: $\Phi[n]=\arctan (Q[n] / I[n])$, where $I[n]$ and $Q[n]$ are the sampled version of the I/Q signals from the radar (see Figure 4), but it presents unwrapping errors because it is restricted to its codomain range $(-\pi / 2, \pi / 2)$. So as to solve these unwrapping limitations, in step 8 of Table 4 , the phase extraction is obtained using the extended differentiate and cross-multiply (DACM) algorithm, which has demonstrated to provide more robust and accurate demodulation results [55]. Finally, the baseline wander, which results from motion artifacts due to fine involuntary movements of the patient, is removed using a method based on empirical mode decomposition (EMD) [56], as shown in Figure 8.

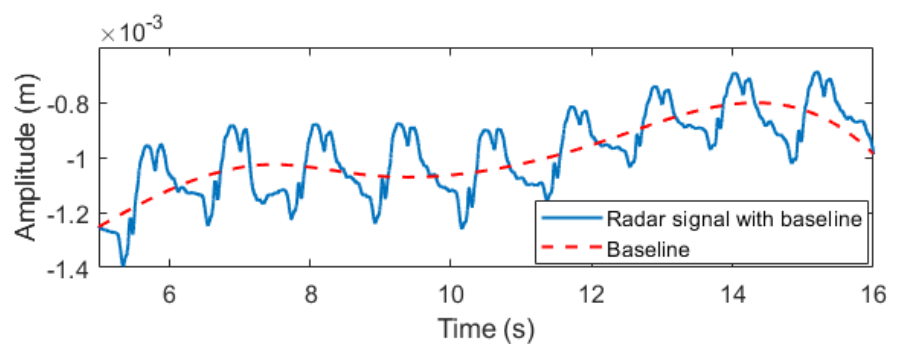

(a)

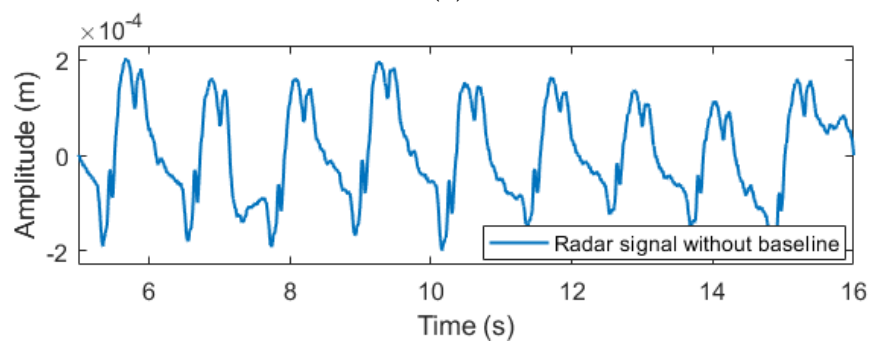

(b)

Figure 8. (a) Radar signal obtained for an apnea measurement and its baseline. (b) Radar signal after removing the baseline using the EMD algorithm. 
Table 4. Pre-processing algorithm steps.

\begin{tabular}{ll}
\hline Pre-Processing Algorithm & \\
\hline $1 \rightarrow s[n]=I[n]+j Q[n]$ & \% Received signal \\
$2 \rightarrow s_{w}[n]=s[n] * w[n]$ & $\% w[n]$ : Window to enhance dynamic range \\
$3 \rightarrow s_{z p}[n]=Z P\left(s_{w}[n]\right)$ & \% Zero-padding added \\
$4 \rightarrow S[f]=F F T\left(s_{z p}[n]\right)$ & \% FFT of each chirp \\
$5 \rightarrow[f 1, f 2]$ determined from $S_{1}[f]$ & \% Target's frequency range from first chirp FFT: $S_{1}[f]$ \\
$6 \rightarrow S_{\text {clipped }}[f, n]=S\left[f_{1}: f_{2}, n\right]$ & \% Clipping of the FFT between $f_{1}$ and $f_{2}$ \\
$7 \rightarrow f_{b}[n]=\max \left(S_{\text {clipped }}[f, n]\right)$ & \% Beat frequency is calculated for each chirp \\
$8 \rightarrow \Phi[n]=D A C M\left(S_{\text {clipped }\left[f_{b}[n], n\right]}\right)$ & \% Phase extraction using DACM algorithm \\
$9 \rightarrow R[n]=\Phi[n] /(4 \pi \lambda)$ & \% Target range is calculated from phase \\
$10 \rightarrow E M D(R[n])$ & \% The baseline wander is removed using EMD \\
\hline
\end{tabular}

\subsubsection{Processing Module for Signals Separation}

After the pre-processing module, the heartbeat and breathing waveforms are extracted using a linear frequency filtering algorithm. It is the simplest algorithm we can use for this purpose, since it only depends on the cut-off frequencies of its filters. These frequencies have been carefully chosen taking into account the nature of the input signal. The filter used to extract the breathing component is defined between $0.05 \mathrm{~Hz}$, to remove the noise and the DC component, and $0.8 \mathrm{~Hz}$, which is limited by the lower cut-off frequency of the heartbeat filter. On the other hand, the upper cut-off frequency of the filter used to extract the heartbeat is dynamically set, ensuring it contains 12 harmonics, number which has been determined after analyzing the MSE error obtained varying the number of harmonics that are contained in the filter. Figure 9 shows that 12 harmonics are needed to fairly reproduce the heartbeat signal. Therefore, the heartbeat filter is defined between $0.8 \mathrm{~Hz}$ and $12 \cdot f_{h b}$, being $f_{h b}$ the heartbeat fundamental frequency.

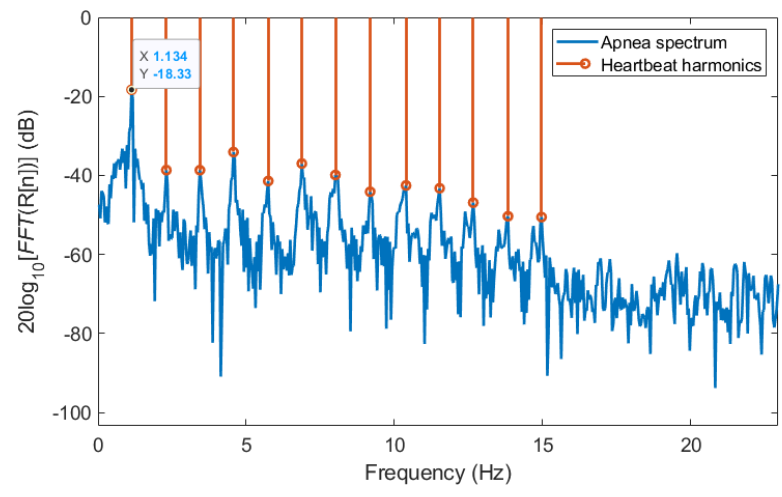

(a)

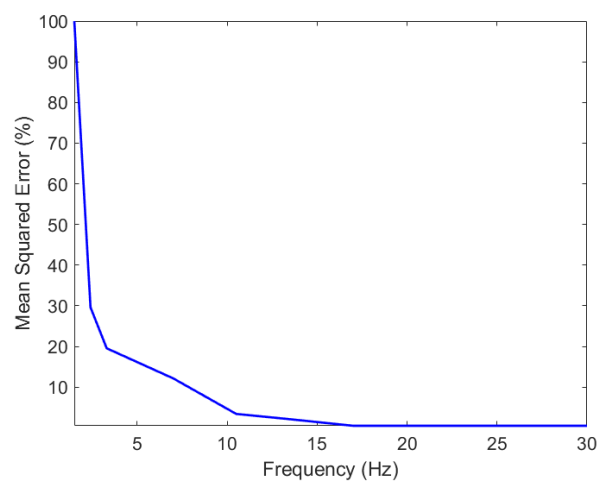

(b)

Figure 9. (a) Spectrum of a measurement in apnea conditions and the harmonics passing through the filter. (b) MSE expressed in \% of the reconstructed heartbeat signal varying the filter cut-off frequency, $f_{c}=k_{2} \cdot f_{h b} . k_{2}$ is the number of harmonics passing through the filter bandwidth and $f_{h b}$ is the fundamental heartbeat frequency.

The steps of the linear filtering algorithm are listed in Table 5. 
Table 5. Linear filtering algorithm steps.

\begin{tabular}{ll}
\hline Linear Filtering Algorithm & \\
\hline $0 \rightarrow$ The window cut-off frequencies are set & \% Breathing: 0.05-0.8 Hz, Heartbeat: $0.8-12 \cdot f_{h b} \mathrm{~Hz}$ \\
$1 \rightarrow W_{b r}[f]$ and $W_{h b}[f]$ & \% Ideal band-pass filter for each signal \\
$2 \rightarrow S_{R}[f]=F F T\{R[n]\}$ & \% FFT of the pre-processed target range \\
$3 \rightarrow S_{b r}[f]=S_{R}[f] \cdot W_{b r}[f]$ & \% Breathing signal in the frequency domain \\
$4 \rightarrow S_{h b}[f]=S_{R}[f] \cdot W_{h b}[f]$ & \% Heartbeat signal in the frequency domain \\
$5 \rightarrow s_{b r}[n]=I F F T\left\{S_{b r}[n]\right\}$ & \% Breathing signal in the time domain \\
$6 \rightarrow s_{h b}[n]=I F F T\left\{S_{h b}[n]\right\}$ & \% Heartbeat signal in the time domain \\
\hline
\end{tabular}

\section{Results}

This section shows the results obtained from the three different experiments carried out, a scheme of the experiments carried out is presented in Figure 10. The first experiment shows the capability of the proposed approach to separate the breathing and heartbeat signals. The second one proves the existing coupling between the breathing and heartbeat signals, also showing that our approach is able to extract an estimate of the HRV sequence in a standoff configuration with different body orientations: anterior and posterior views. And finally, the third experiment has been developed to reproduce a real-case scenario, where two persons are monitored simultaneously.

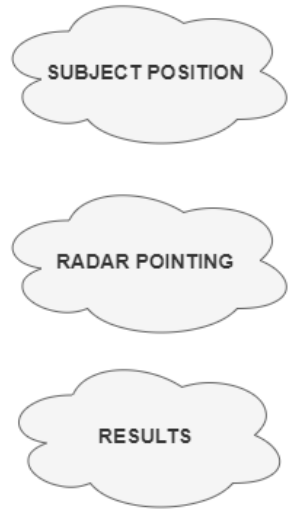

Experiment 1.1

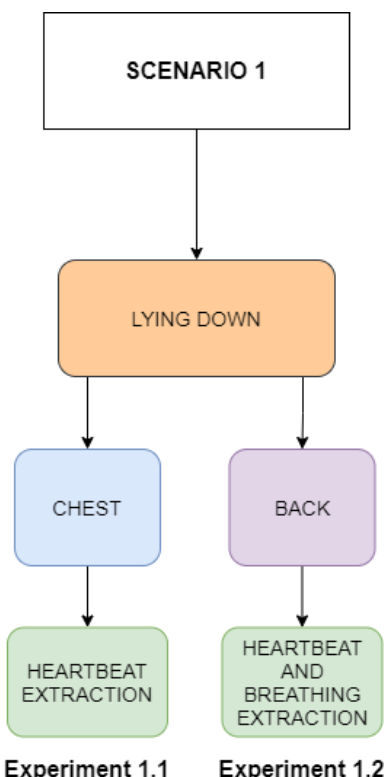

Figure 10. Scheme of the experiments carried out.
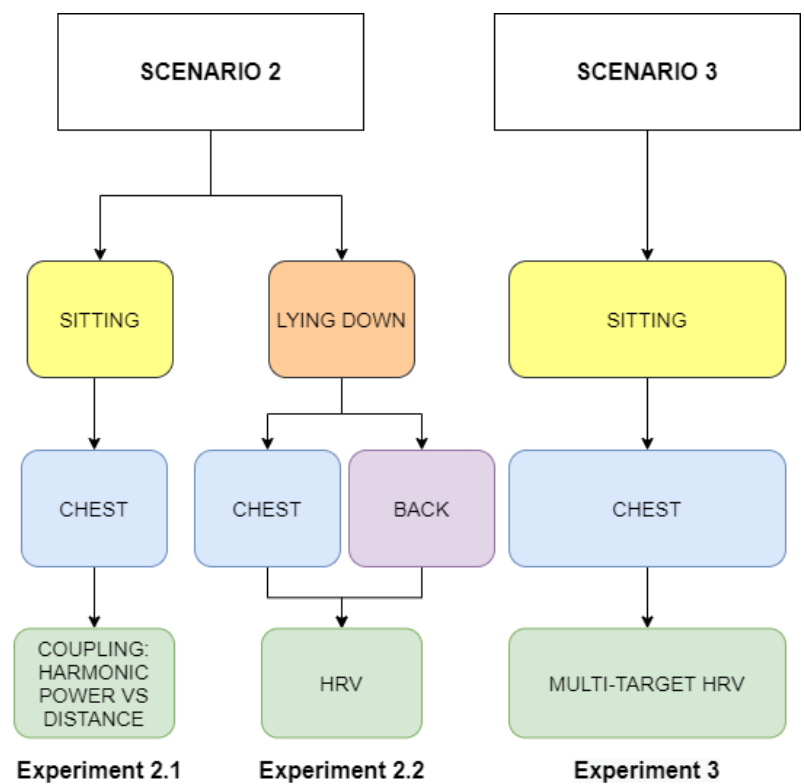

Experiment 3

\subsection{Breathing and Heartbeat Information Extraction}

Our results show that the system is not only capable of identifying the breathing and heartbeat rates, but it can capture the contributions from these two organs in the radar signals, and we can separate these joint contributions into its breathing and heartbeat components. Results also show that different parameters such as heart rate and more sophisticated ones like the HRV can be derived from the sequences extracted, which might be useful as monitoring tools.

Firstly, a 22-year-male subject has been monitored in apnea condition, the subject was lying down at $0.2 \mathrm{~m}$ from the radar setup, where the radar is pointing to the subject's chest (see Figure 11a). The distance was chosen to reduce the field of view of the radar to a region which mostly (FoV of $10 \mathrm{~cm}^{2}$ ) belongs to the heart location [26]. The resulting waveform and the reference ECG are shown in Figure 12. 


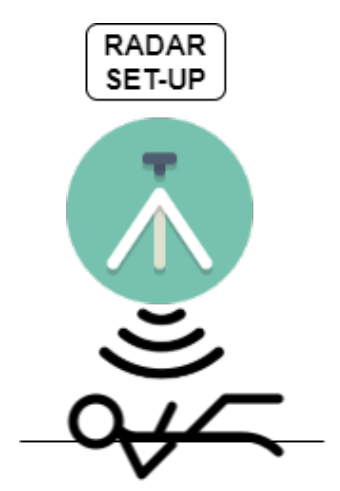

(a)

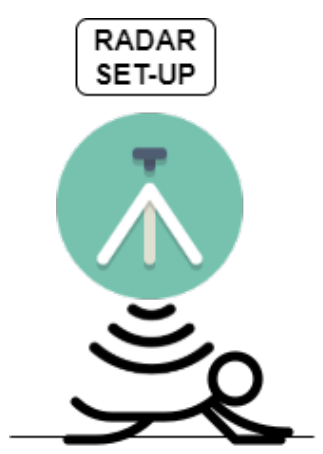

(b)

Figure 11. (a) Experimental scenario 1.1 diagram. (b) Experimental scenario 1.2 diagram.

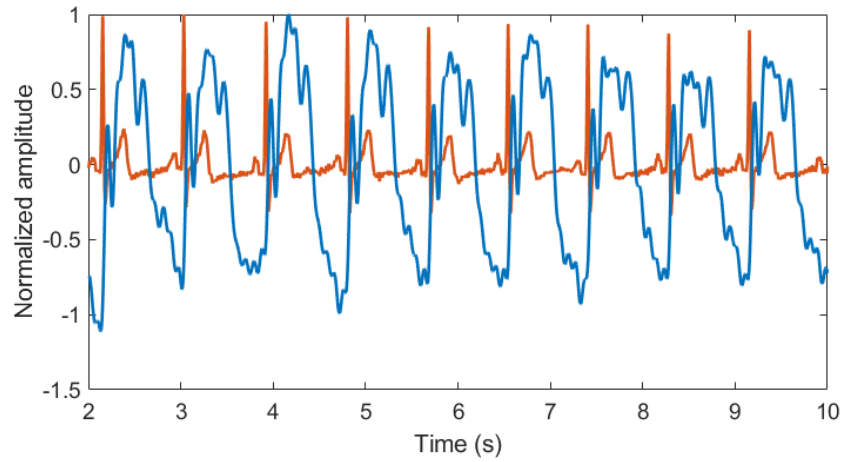

(a)

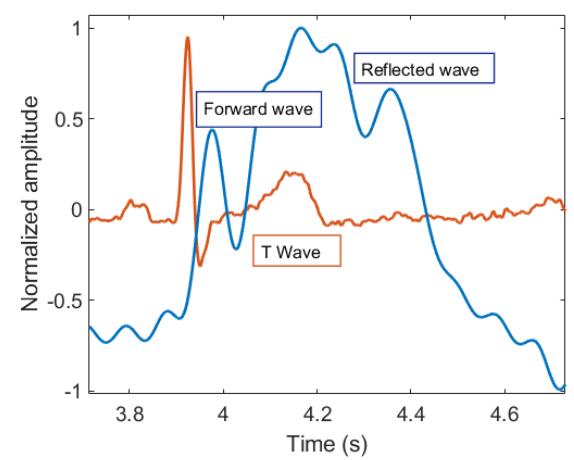

(b)

Figure 12. (a) Heartbeat waveform extracted from a subject holding his breath with its reference ECG, for a person with a heart rate between $70-71$ beats $/ \mathrm{min}$. (b) Zoom of one pulse corresponding to the heartbeat waveform extracted with the radar and its associated ECG.

As previously stated in [26], the extracted heartbeat waveform depends on the orientation of the radar, so the beat shape can lightly differ between measurements taken using the anterior or posterior view. However, the characteristic points providing significant diagnostic information can be easily identified, being congruent with the prototypical shape shown in [57] (Figure 12b). The radar sequence presents the prototypical plot of the arterial pulse waveform, which is composed of a forward and backward wave. The forward wave represents the traveling wave generated by contraction of the left ventricle of the heart, while the reflected wave is the traveling wave generated by reflection from peripheral arteries [58].

The next experiment represents a more realistic scenario: a 22-year-male is lying down, breathing normally, and the radar is placed $1 \mathrm{~m}$ away from the subject, pointing to its back (see Figure 11b). Figure 13 shows in green the chest displacement obtained with the radar, where the heartbeat overlays the breathing waveform, which is the dominant component due to a 10:1 amplitude ratio between both signals. Thus, the chest displacement roughly corresponds with the breathing signal. Moreover, the normalized heartbeat (in blue) and the reference ECG (in red) are also displayed. These results evidence that, despite the heartbeat waveform appears with an amplitude distortion for some periods, there is a clear synchrony between the ECG and the heartbeat waveform. Besides, Figure 13 shows the modulations in both the amplitude and in the pulse period sequence of the ECG, which are highly correlated with the breathing: Breathing directly modulates the amplitude of the ECG; and, exhalations 
increase the pulse periods, whereas inhalations decrease the pulse periods. These effects were expected and have been widely analyzed in the literature [45,59].

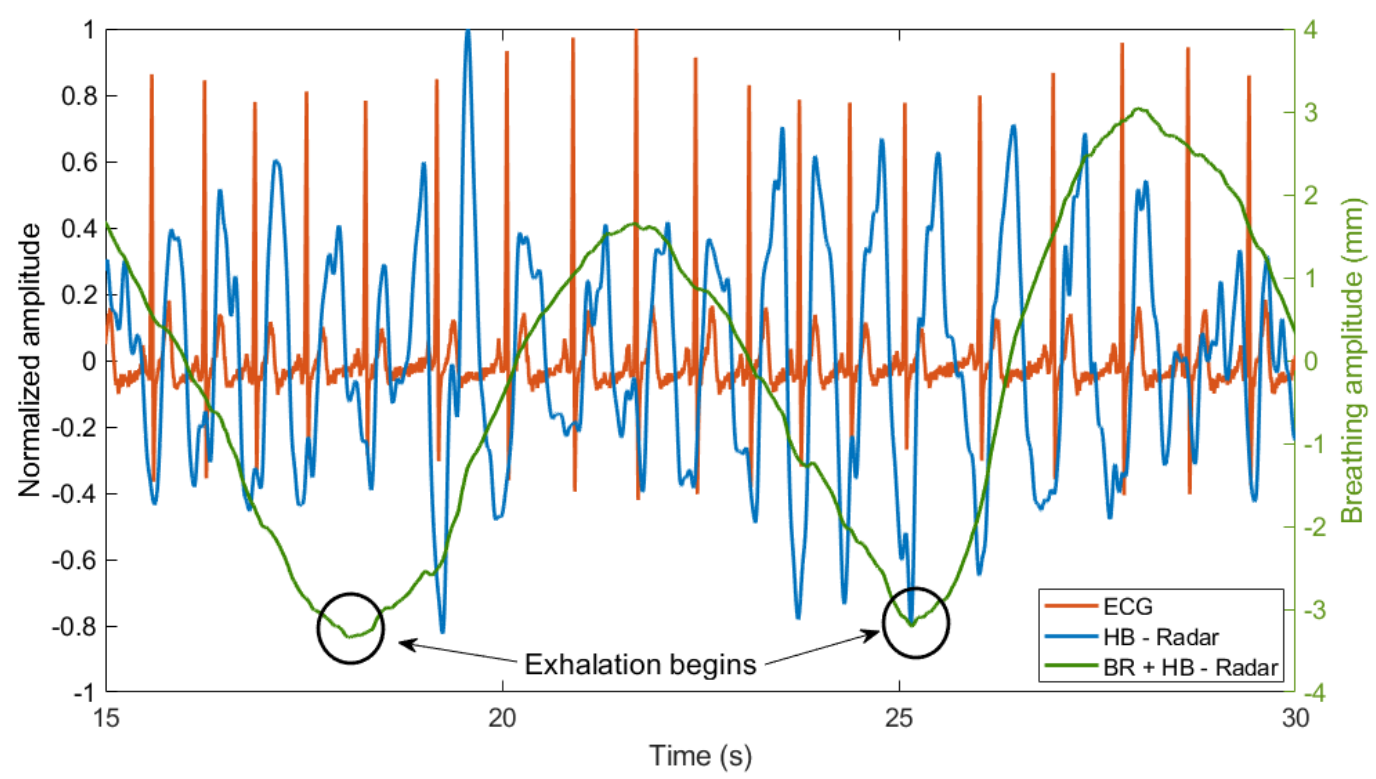

Figure 13. Heartbeat waveform extracted from a breathing subject compared with its reference ECG. It also shows the relative displacement acquired with the radar, which contains the breathing and heartbeat signals. The subject has a respiratory rate between $8-9$ breaths / min and a heart rate between $77-78$ beats $/ \mathrm{min}$.

\subsection{Analysis of Breathing and Cardiac Activity Coupling}

The following results show the capability of the system to measure the coupling between the breathing and the cardiac activity. This effect can be observed in terms of power, as can be seen in the spectrum of the joint cardiorespiratory signal (Figure 14a), which identifies the fundamental frequencies $\left(f_{b r}, f_{h b}\right)$, their harmonics $\left(k_{1} f_{b r}, k_{2} f_{h b}\right)$, and the mixed frequencies $\left(k_{1} f_{b r}+k_{2} f_{h b}\right)$ (being $f_{h b}$ and $f_{b r}$ the fundamental frequency of the heartbeat and respiratory components respectively; and, $k_{1}$ and $k_{2}$ the ordinals of the harmonics). This spectrum can be used to measure the dynamic range of these two signals (Figure 14b) where it is clear that the amplitude of the fundamental frequency of the cardiac activity increases during breathing. This coupling can also be shown in the secondary parameters extracted like the HRV or RSA. These last parameters have been analyzed in Section 3.2. 


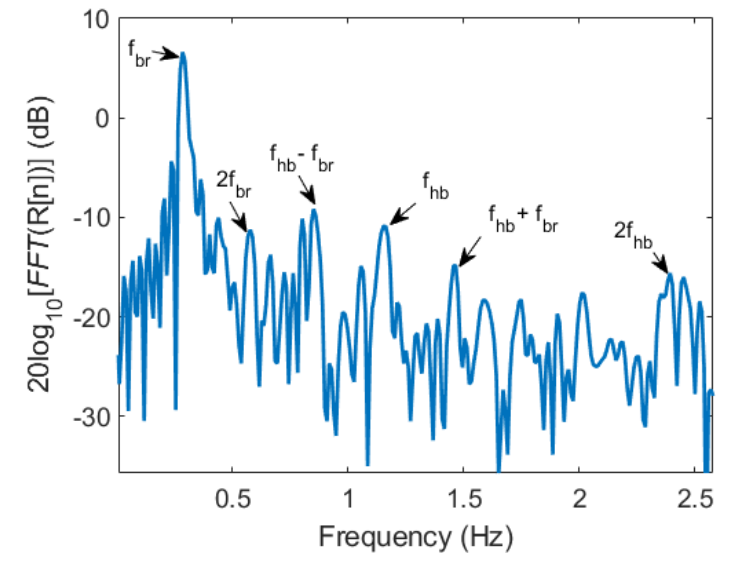

(a)

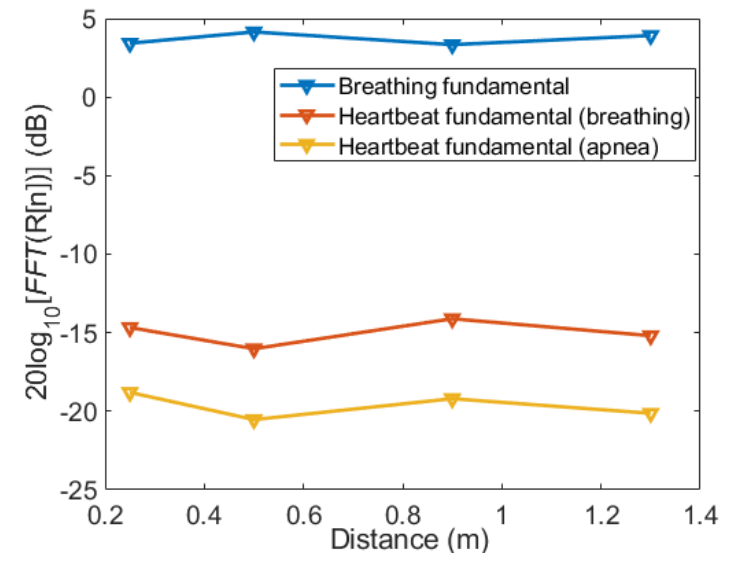

(b)

Figure 14. (a) Breathing and heartbeat harmonics identified in a breathing measurement spectrum. (b) Spectral analysis of the breathing and heartbeat fundamental components when the subject is breathing and when the subject holds his breath.

\section{Heart Rate Variability}

In this section, the experiment consists of measuring a 22-year male in a lying-down position with the radar pointing either to the chest (anterior view) or to the back (posterior view). These scenarios are analyzed when the person is breathing or during apnea. Then, the HRV calculated from the ECG is compared to the HRV obtained from the radar measurement (rHRV). During breathing, the HRV is compared with the breathing waveform to observe how the breathing affects the heart rate. The existing correlation between the HRV and the breathing signal was previously analyzed by H. Kobayashi in [60], where the HRV was computed from the ECG and the breathing signal was acquired with a spirometer.

The HRV has been computed measuring the R-R distance, while the rHRV has been estimated using a very simple method based on measuring the distance between rising signal zero-crossings, with a minimum distance between adjacent zero-crossing of $\frac{1}{1.2 f_{h b}}$, where $f_{h b}$ is the heartbeat fundamental frequency. Figure 15 shows the rHRV extraction from the radar heartbeat waveform.

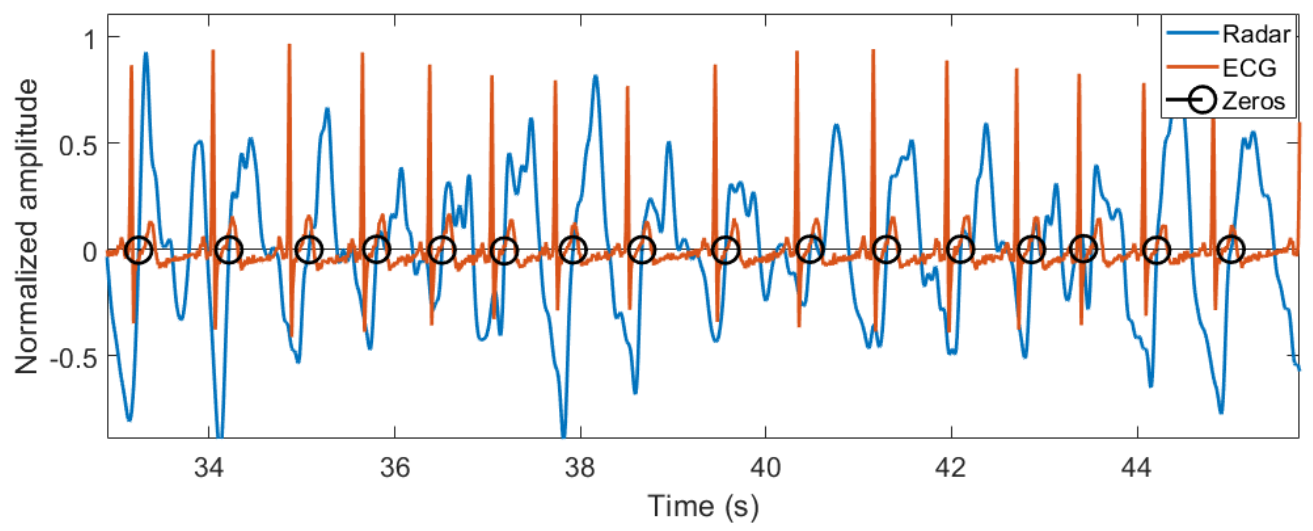

Figure 15. Radar points selected to perform the rHRV extraction.

Results obtained with a posterior view are illustrated in Figure 16a, where the HRV and rHRV sequences are depicted along with the error taking HRV as a reference. The breathing has been represented so as to show the RSA effect, where the breathing amplitude affects the heart rate. Moreover, it is observed that the same correlation between the HRV and the breathing signal obtained 
by H. Kobatashi is reproduced in Figure 16a. On the other hand, the same experiment has been carried out to confirm that in an apnea scenario the heart rate is almost stable, since it is not affected by breathing. These results can be observed in Figure 16b.

Analogously, the same procedure described above has been carried out to analyze the measurements with an anterior view. The HRV and rHRV sequences obtained during breathing are shown in Figure 16c. Moreover, the apnea scenario has also been analyzed Figure 16d.

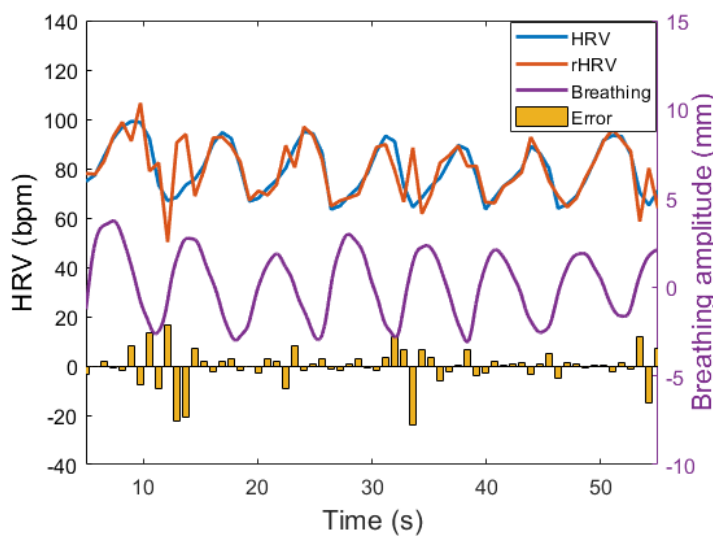

(a) Breathing subject (posterior view)

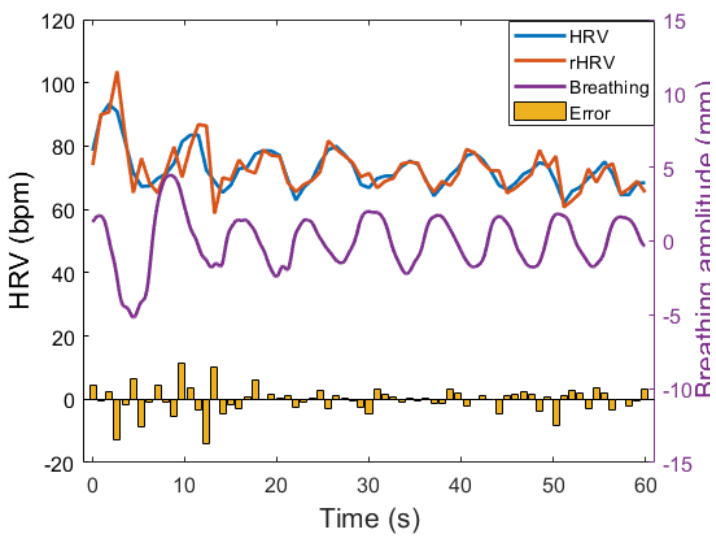

(c) Breathing subject (anterior view)

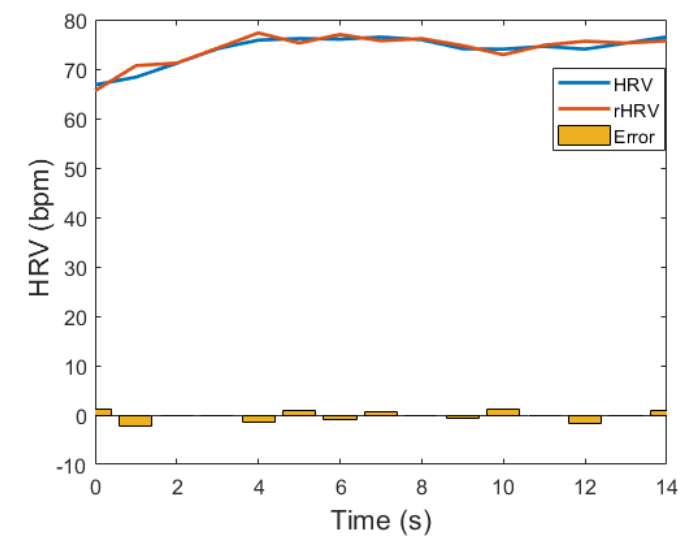

(b) Subject holding his breath (posterior view)

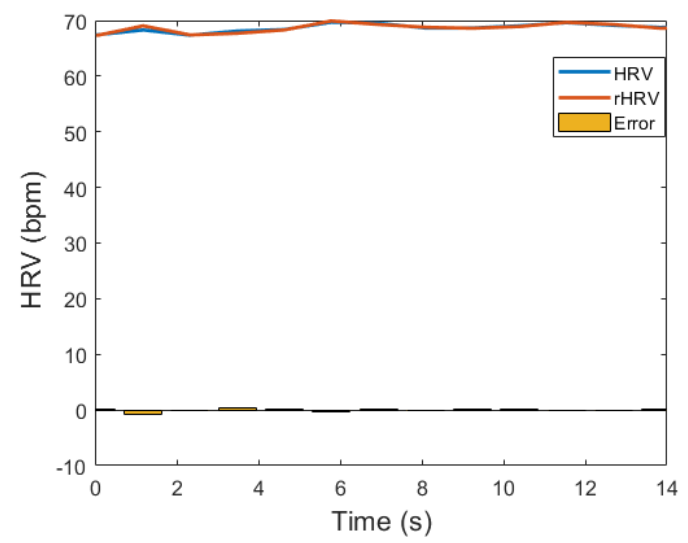

(d) Subject holding his breath (anterior view)

Figure 16. From top to down, for the four different scenarios: the HRV and rHRV sequences, and the error using HRV as a reference are represented as Error. In those scenarios where the subject is not holding his breath the breathing signal is displayed (a) Scenario 1: Breathing subject with the radar pointing towards the posterior view. The error mean is 0.21 beats $/ \mathrm{min}$ and its standard deviation is 7.24. (b) Scenario 2: Subject in apnea with the radar pointing towards the posterior view. The error mean is -0.28 beats $/ \mathrm{min}$ and its standard deviation is 1.08. (c) Scenario 3: Breathing subject with the radar pointing towards the anterior view. Its error mean is -0.17 beats $/ \mathrm{min}$ and its standard deviation is 4.12. (d) Scenario 4: Subject in apnea with the radar pointing towards the anterior view. Its error mean is -0.004 beats $/ \mathrm{min}$ and its standard deviation is 0.27 .

\subsection{Multi-Detection}

In this section, an experiment is performed to prove the system capability to measure the vital signs of multiple targets at the same time. Thus, the scenario consists of measuring two males of 21 and 25 years, sitting in front of the radar setup, at 1.2 and $1.6 \mathrm{~m}$ (Figure 17a), and Figure 17b shows that these two persons can be clearly separated in the frequency domain. 
The chest displacement waveforms captured and the rHRV sequences computed for each subject are displayed in Figure 18.

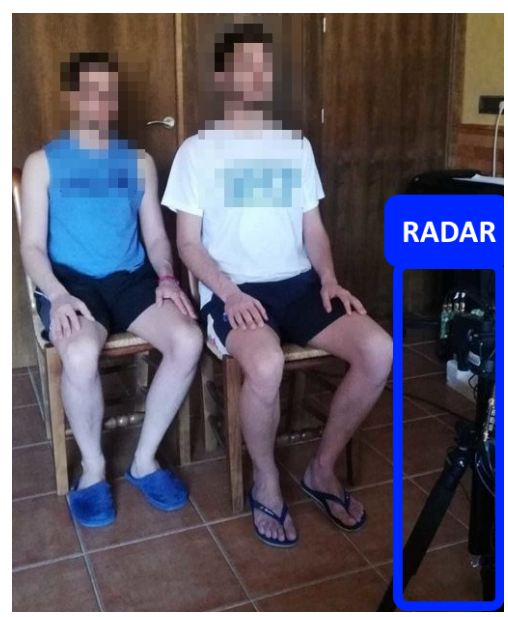

(a)

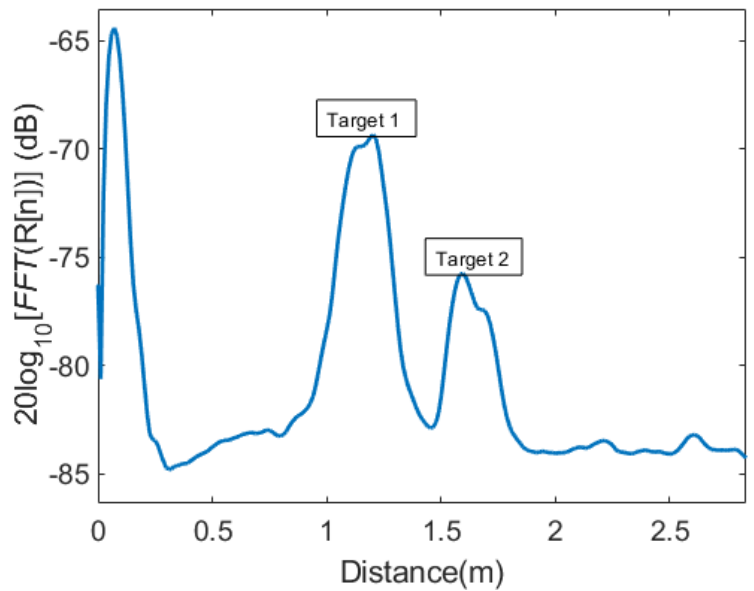

(b)

Figure 17. (a) Multi-target experiment scenario. (b) Frequency spectrum of the captured radar signal, where the two targets are clearly separated at 1.2 and $1.6 \mathrm{~m}$.

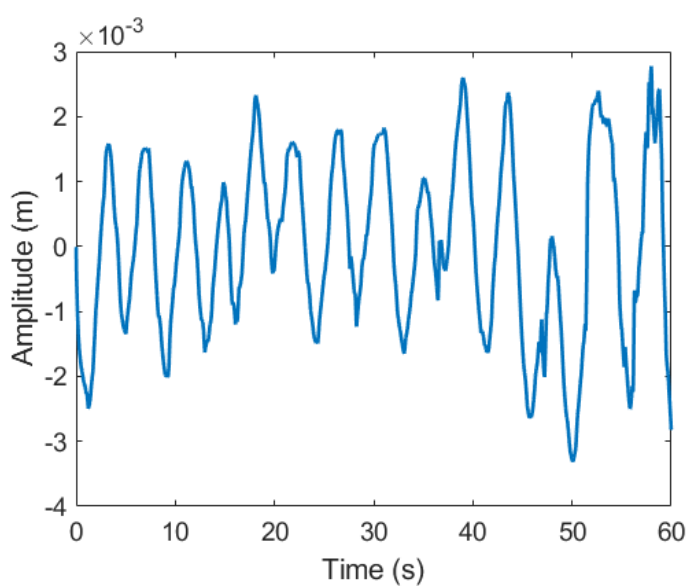

(a) Radar signal (target 1)

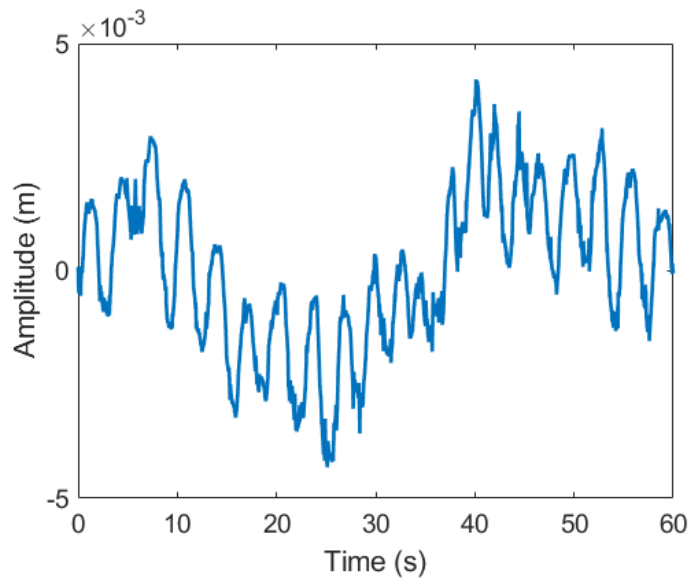

(c) Radar signal (target 2)

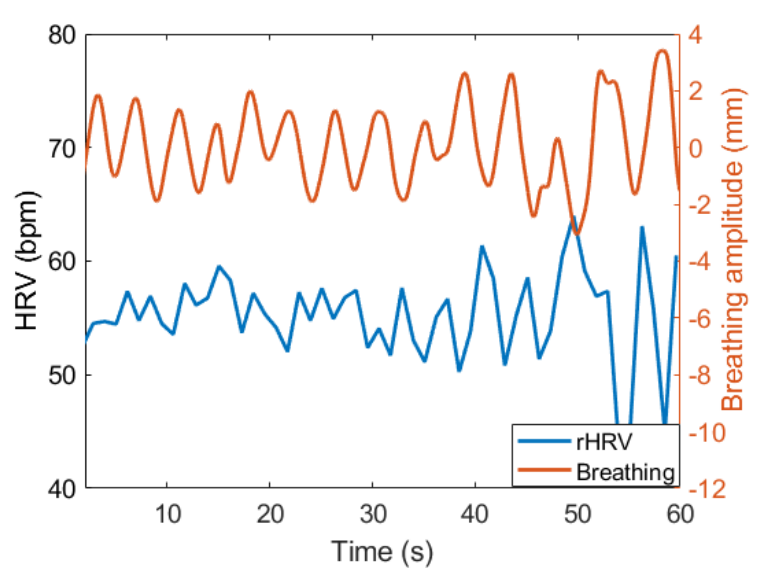

(b) rHRV (target 1)

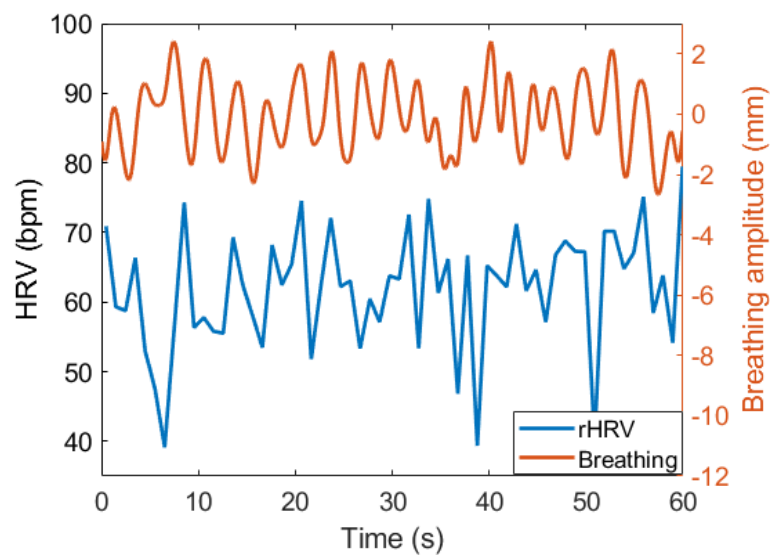

(d) rHRV (target 2)

Figure 18. (a) Radar signal obtained from target 1 after performing the pre-processing algorithm. (b) rHRV extracted from the target located at $1.2 \mathrm{~m}$. (c) Radar signal obtained from target 2 after the pre-processing algorithm. (d) rHRV extracted from the target which is located at $1.6 \mathrm{~m}$. 


\section{Discussion}

Although the idea of contactless monitoring of cardiorespiratory function using radar techniques is not new, in the last few years it has become a significant research topic due to the affordability and size of current radar devices, and due to its potential use in certain applications in which the monitoring device cannot be attached to the patient. However, despite of the obvious potential, a large amount of research is still required before being used in the clinic.

This paper presents the results obtained with a commercial low cost $122 \mathrm{GHz} F M C W$ radar device, whose setup has been modified to fit the current application. We use an FMCW radar to isolate persons due to its position and then measure the phase differences occurring in the reflected wave with respect to the one emitted due to displacements of the target. In contrast to other potential radar setups, which measure the frequency shift due to the velocity changes (i.e., the Doopler effect), the FMCW scheme is considered more adequate for our purpose of monitoring the cardiorespiratory function due to its capacity to separate targets in distance, allowing simultaneous multi-target monitoring. Moreover, the selection of high working frequencies, such as $122 \mathrm{GHz}$, results in a higher sensitivity to small target range variations, since the obtained phase is proportional to the range variations through the radar central frequency, with an accuracy of $2 \mu \mathrm{m}$ (Figure 3).

The signal obtained with the radar corresponds to the combined displacement effects due to the breathing and heart beating movements. Initially, both effects are merged together, also in combination with certain artifacts due to the involuntary movements of the patient. The removal of the artifacts and the separation of these two sources of information are challenging aspects currently being addressed in the literature [25-27] with promising results but still in its infancy.

In order to remove the movement artifacts, we have made use of an EMD based algorithm. EMD is an adaptive time-space analysis method suitable for processing non-linear and non-stationary series. EMD partitions a series into its Intrinsic Mode Functions (IMF) (also called modes) without leaving the time domain. EMD has been used in a wide range of applications to remove the mode corresponding to the baseline wander, having demonstrated a significant ability to solve similar problems $[61,62]$. Its use in our domain of application has also led to very good results, although other more evolutioned methods might be used, such as Variational Mode Decomposition (VMD) [63].

In this work, the separation of the breathing from the heartbeat has been carried out using a simple linear band pass filter with upper cut-off frequencies adjusted to obtain 12 harmonics of the signal. Although this is probably the simplest scheme that might be used for this purpose, results have demonstrated that the synchronous relationship with the ECG signal used as a reference is kept (Figure 15). Results show that the pulse period perturbation effects present in the ECG due to the breathing process also appear in the heartbeat signal extracted. Such synchronous relationship is crucial to derive certain monitoring sequences, such as the HRV and/or the RSA, typically extracted from the ECG. In any case, the information obtained from the pulse periods of the heartbeat signals represents a contactless alternative approach to estimate the HRV sequences, opening the possibility of a wide range of monitoring capabilities, as those using the ECG as a source [41,42].

Regarding the shape of the heartbeat sequence obtained, literature has suggested very strong shape correlations with respect to the arterial pressure wave [26], with two phases clearly identifiables: one corresponding to the forward wave, and another to the reflected one. Despite these two phases are easily distinguishable in Figure $12 b$, our results suggest that the signal obtained is correlated with a time shifted mixture of the effects introduced by ventricular and atrial pressures [57].

On the other hand, it is important to highlight that shape and time-shift differences of the heartbeat signal extracted are influenced by the FoV of the radar [26], since it integrates the displacement information obtained from all points in the whole area illuminated by the radar. The study of this effect also requires a further research from our side, adapting the FoV of the radar with the radar configuration.

Despite of the interesting results and the simplicity of the linear filtering approach used, a more accurate filtering algorithm is required to extract additional in depth conclusions. In any case, 
the objective of this paper has not been the optimization of the source separation algorithms, but also to provide evidences of the separability of the signals and artifacts, along with providing evidences on the potential use of the radar signal obtained to derive significant monitoring characteristics that are widely used in the clinic.

Regarding the possibility to accurately obtain the HRV sequences from the radar acquired signal, results suggest a strong potential due to the perfect synchronization obtained between the ECG and the heartbeat extracted. However, a more accurate algorithm is required to identify the starting of the pulse periods in order to reduce the error. The one used is just based on the identification of the zero-crossings, this is not an error free procedure due to noisy effects present in the signal or due to the inherent shape variability of the pulses obtained. As expected, the errors obtained during the rHRV estimation with respect to the standard HRV are much lower in apnea situations due to the inherent lower heart rate variability; whereas logically increase in the breathing scenario. In any case, the scheme proposed to extract the rHRV has provided promising results even in a multi-target scenario. As was previously stated, multi-target monitoring is the main reason behind the choice of FMCW radar over other radar technologies to monitor several subjects simultaneously. Moreover, FMCW technology allows to measure not only the vital signs of each subject, but also retrieves the location of the subject, allowing its tracking. Information about target's position is valuable data in rescue working and tele-health scenarios [6,7].

\section{Conclusions}

A modified commercial $122 \mathrm{GHz}$ frequency-modulated continuous-wave radar is used in a standoff configuration to monitor cardiorespiratory activity.

This low cost system allows different hardware configurations to analyze the correlation between the heart electrical response -measured with an ECG- and its mechanical response measured with the radar. Additionally, our results evidence the coupling between breathing and heartbeat, also showing that the HRV sequence derived from the radar signal can identify the RSA effect. Finally, the radar is tested in a simultaneous multi-target scenario, demonstrating its monitoring capabilities in assisting living.

Although more complex algorithms have to be developed for alleviating some artifacts and improving robustness of the measurements, assisting living systems will incorporate radar technology in its deployment in real life environments.

Author Contributions: Conceptualization, F.G.-R., E.A. and J.G.; methodology, E.A., J.I.G.-L. and J.G.; validation, E.A. and J.G.; formal analysis, E.A.; investigation, E.A., F.G.-R., C.H., D.M., J.G. and J.I.G.-L.; writing, review and editing, E.A., F.G.-R., J.G. and J.I.G.-L.; funding acquisition, J.G. All authors have read and agreed to the published version of the manuscript.

Funding: This work was supported in part by funding from the Spanish Ministry of Science, Innovation and Universities within projects TEC2017-87061-C3-1-R (CIENCIA/AEI/FEDER, UE) and DPI2017-83405-R. The work of E. Antolinos was supported by an FPU Fellowship granted by the Spanish Ministry of Education (FPU18/01525).

Conflicts of Interest: The authors declare no conflict of interest.

\section{Abbreviations}

The following abbreviations are used in this manuscript:

$\begin{array}{ll}\text { ADC } & \text { Analogical-digital converter } \\ \text { ANS } & \text { Autonomic nervous system } \\ \text { APFT } & \text { Almost-Periodic Fourier Transform } \\ \text { BCG } & \text { Ballistocardiograph } \\ \text { CW } & \text { Continuous-wave } \\ \text { DACM } & \text { Differentiate and cross-multiply } \\ \text { ECG } & \text { Electrocardiogram }\end{array}$




$\begin{array}{ll}\text { EMD } & \text { Empirical mode decomposition } \\ \text { FFT } & \text { Fast Fourier Transform } \\ \text { FMCW } & \text { Frequency modulated continuous-wave } \\ \text { FoV } & \text { Field of view } \\ \text { HRV } & \text { Heart rate variability } \\ \text { ISM } & \text { Industrial, scientific and medical } \\ \text { IMF } & \text { Intrinsic Mode Functions } \\ \text { MIMO } & \text { Multiple-input multiple-output } \\ \text { MMIC } & \text { Monolithic microwave integrated circuit } \\ \text { MSE } & \text { Mean Squared Error } \\ \text { PFD } & \text { Phase-frequency detector } \\ \text { PLL } & \text { Phase-locked loop } \\ \text { PPG } & \text { Photopletysmogram } \\ \text { rHRV } & \text { HRV from the radar measurement } \\ \text { RSA } & \text { Respiratory sinus arrhythmia } \\ \text { RVP } & \text { Residual video phase } \\ \text { SCG } & \text { Seismocardiograph } \\ \text { SNR } & \text { Signal-to-noise ratio } \\ \text { VCO } & \text { Voltage-controlled oscillator } \\ \text { VMD } & \text { Variational Mode Decomposition }\end{array}$

\section{References}

1. Boric-Lubecke, O.; Lubecke, V.M.; Droitcour, A.D.; Park, B.K.; Singh, A. (Eds.) Doppler Radar Physiological Sensing; Wiley Series in Biomedical Engineering and Multi-Disciplinary Integrated Systems; IEEE: New York, NY, USA; Wiley: Hoboken, NJ, USA, 2016.

2. Antognoli, L.; Marchionni, P.; Nobile, S.; Carnielli, V.; Scalise, L. Assessment of cardio-respiratory rates by non-invasive measurement methods in hospitalized preterm neonates. In Proceedings of the 2018 IEEE International Symposium on Medical Measurements and Applications (MeMeA), Rome, Italy, 11-13 June 2018; pp. 1-5. [CrossRef]

3. Tataraidze, A.B.; Anishchenko, L.N.; Korostovtseva, L.S.; Bochkarev, M.V.; Sviryaev, Y.V. Non-contact Respiratory Monitoring of Subjects with Sleep-Disordered Breathing. In Proceedings of the 2018 IEEE International Conference “Quality Management, Transport and Information Security, Information Technologies" (IT\&QM\&IS), St. Petersburg, Russia, 24-28 September 2018; pp. 736-738. [CrossRef]

4. Konstam, M.A. Home Monitoring Should Be the Central Element in an Effective Program of Heart Failure Disease Management. Circulation 2012, 125, 820-827. [CrossRef]

5. Darkins, A.; Ryan, P.; Kobb, R.; Foster, L.; Edmonson, E.; Wakefield, B.; Lancaster, A.E. Care Coordination/Home Telehealth: The Systematic Implementation of Health Informatics, Home Telehealth, and Disease Management to Support the Care of Veteran Patients with Chronic Conditions. Telemed. E-Health 2008, 14, 1118-1126. [CrossRef] [PubMed]

6. Gurbuz, S.Z.; Amin, M.G. Radar-Based Human-Motion Recognition With Deep Learning: Promising Applications for Indoor Monitoring. IEEE Signal Process. Mag. 2019, 36, 16-28. [CrossRef]

7. Le Kernec, J.; Fioranelli, F.; Ding, C.; Zhao, H.; Sun, L.; Hong, H.; Lorandel, J.; Romain, O. Radar Signal Processing for Sensing in Assisted Living: The Challenges Associated With Real-Time Implementation of Emerging Algorithms. IEEE Signal Process. Mag. 2019, 36, 29-41. [CrossRef]

8. Vieau, S.; Iaizzo, P.A. Basic ECG Theory, 12-Lead Recordings, and Their Interpretation. In Handbook of Cardiac Anatomy, Physiology, and Devices; Iaizzo, P.A., Ed.; Springer International Publishing: Cham, Switzerland, 2015; pp. 321-334. [CrossRef]

9. Fusco, A.; Locatelli, D.; Onorati, F.; Durelli, G.C.; Santambrogio, M.D. On how to extract breathing rate from PPG signal using wearable devices. In Proceedings of the 2015 IEEE Biomedical Circuits and Systems Conference (BioCAS), Atlanta, GA, USA, 22-24 October 2015; pp. 1-4. [CrossRef] 
10. Starr, I.; Rawson, A.J.; Schroeder, H.A.; Joseph, N.R. Studies on the estimation of cardiac output in man, and of abnormalities in cardiac function, from the heart's recoil and the blood's impact; the ballistocardiogram. Am. J. Physiol. Leg. Content 1939, 127, 1-28. [CrossRef]

11. Zanetti, J.; Salerno, D. Seismocardiography: A technique for recording precordial acceleration. In Computer-Based Medical Systems-Proceedings of the Fourth Annual IEEE Symposium; IEEE Computer Society Press: Baltimore, MD, USA, 1991; pp. 4-9. [CrossRef]

12. Wu, H.Y.; Rubinstein, M.; Shih, E.; Guttag, J.; Durand, F.; Freeman, W. Eulerian video magnification for revealing subtle changes in the world. ACM Trans. Graph. 2012, 31, 1-8. [CrossRef]

13. Hong, H. Noninvasive detection of cardiovascular pulsations by optical Doppler techniques. J. Biomed. Opt. 1997, 2, 382. [CrossRef] [PubMed]

14. Abbas, A.K.; Heimann, K.; Jergus, K.; Orlikowsky, T.; Leonhardt, S. Neonatal non-contact respiratory monitoring based on real-time infrared thermography. BioMedical Eng. OnLine 2011, 10, 93. [CrossRef]

15. Bruser, C.; Antink, C.H.; Wartzek, T.; Walter, M.; Leonhardt, S. Ambient and Unobtrusive Cardiorespiratory Monitoring Techniques. IEEE Rev. Biomed. Eng. 2015, 8, 30-43. [CrossRef]

16. Lin, J. Noninvasive microwave measurement of respiration. Proc. IEEE 1975, 63, 1530. [CrossRef]

17. Li, C.; Peng, Z.; Huang, T.Y.; Fan, T.; Wang, F.K.; Horng, T.S.; Munoz-Ferreras, J.M.; Gomez-Garcia, R.; Ran, L.; Lin, J. A Review on Recent Progress of Portable Short-Range Noncontact Microwave Radar Systems. IEEE Trans. Microw. Theory Tech. 2017, 65, 1692-1706. [CrossRef]

18. Chen, K.-M.; Huang, Y.; Zhang, J.; Norman, A. Microwave life-detection systems for searching human subjects under earthquake rubble or behind barrier. IEEE Trans. Biomed. Eng. 2000, 47, 105-114. [CrossRef] [PubMed]

19. Wang, S.; Pohl, A.; Jaeschke, T.; Czaplik, M.; Kony, M.; Leonhardt, S.; Pohl, N. A novel ultra-wideband $80 \mathrm{GHz}$ FMCW radar system for contactless monitoring of vital signs. In Proceedings of the 2015 37th Annual International Conference of the IEEE Engineering in Medicine and Biology Society (EMBC), Milan, Italy, 25-29 August 2015; pp. 4978-4981. [CrossRef]

20. Lee, Y.S.; Pathirana, P.N.; Steinfort, C.L.; Caelli, T. Monitoring and Analysis of Respiratory Patterns Using Microwave Doppler Radar. IEEE J. Transl. Eng. Health Med. 2014, 2, 1-12. [CrossRef] [PubMed]

21. Droitcour, A.; Lubecke, V.; Lin, J.; Boric-Lubecke, O. A microwave radio for Doppler radar sensing of vital signs. In Proceedings of the 2001 IEEE MTT-S International Microwave Sympsoium Digest (Cat. No.01CH37157), Phoenix, AZ, USA, 20-24 May 2001; Volume 1, pp. 175-178. [CrossRef]

22. Massagram, W.; Lubecke, V.; Host-Madsen, A.; Boric-Lubecke, O. Assessment of Heart Rate Variability and Respiratory Sinus Arrhythmia via Doppler Radar. IEEE Trans. Microw. Theory Tech. 2009, 57, 2542-2549. [CrossRef]

23. Wang, J.; Wang, X.; Zhu, Z.; Huangfu, J.; Li, C.; Ran, L. 1-D Microwave Imaging of Human Cardiac Motion: An Ab-Initio Investigation. IEEE Trans. Microw. Theory Tech. 2013, 61, 2101-2107. [CrossRef]

24. Petrovic, V.L.; Jankovic, M.M.; Lupsic, A.V.; Mihajlovic, V.R.; Popovic-Bozovic, J.S. High-Accuracy Real-Time Monitoring of Heart Rate Variability Using $24 \mathrm{GHz}$ Continuous-Wave Doppler Radar. IEEE Access 2019, 7, 74721-74733. [CrossRef]

25. Will, C.; Shi, K.; Schellenberger, S.; Steigleder, T.; Michler, F.; Weigel, R.; Ostgathe, C.; Koelpin, A. Local Pulse Wave Detection Using Continuous Wave Radar Systems. IEEE J. Electromagn. RF Microwaves Med. Biol. 2017, 1, 81-89. [CrossRef]

26. Vinci, G.; Lindner, S.; Barbon, F.; Mann, S.; Hofmann, M.; Duda, A.; Weigel, R.; Koelpin, A. Six-Port Radar Sensor for Remote Respiration Rate and Heartbeat Vital-Sign Monitoring. IEEE Trans. Microw. Theory Tech. 2013, 61, 2093-2100. [CrossRef]

27. Dong, S.; Zhang, Y.; Ma, C.; Zhu, C.; Gu, Z.; Lv, Q.; Zhang, B.; Li, C.; Ran, L. Doppler Cardiogram: A Remote Detection of Human Heart Activities. IEEE Trans. Microw. Theory Tech. 2020, 68, 1132-1141. [CrossRef]

28. Petkie, D.T.; Benton, C.; Bryan, E. Millimeter wave radar for remote measurement of vital signs. In Proceedings of the 2009 IEEE Radar Conference, Pasadena, CA, USA, 4-8 May 2009; pp. 1-3.

29. Lee, H.; Kim, B.H.; Yook, J.G. Path Loss Compensation Method for Multiple Target Vital Sign Detection with 24-GHz FMCW Radar. In Proceedings of the 2018 IEEE Asia-Pacific Conference on Antennas and Propagation (APCAP), Auckland, New Zealand, 5-8 August 2018; pp. 100-101. [CrossRef] 
30. Ahmad, A.; Roh, J.C.; Wang, D.; Dubey, A. Vital signs monitoring of multiple people using a FMCW millimeter-wave sensor. In Proceedings of the 2018 IEEE Radar Conference (RadarConf18), Oklahoma City, OK, USA, 23-27 April 2018; pp. 1450-1455. [CrossRef]

31. Prat, A.; Blanch, S.; Aguasca, A.; Romeu, J.; Broquetas, A. Collimated Beam FMCW Radar for Vital Sign Patient Monitoring. IEEE Trans. Antennas Propag. 2019, 67, 5073-5080. [CrossRef]

32. Betancur, J. Multimodal Image Registration for the Characterization of the Hypertrophic Cardiomyopathy and the Cardiac Asynchronism. Ph.D. Thesis, Université Rennes, Rennes, France, 2014.

33. Sermesant, M. Modèle électromécanique du coeur pour l'analyse d'image et la simulation (Electromechanical Model of the Heart for Image Analysis and Simulation). Ph.D. Thesis, Universite Nice Sophia Antipolis, Nice, France, 2003.

34. OpenStax. Anatomy and Physiology; OpenStax CNX: Houston, TX, USA, 2016; Chapter 19.

35. Esper, S.A.; Pinsky, M.R. Arterial waveform analysis. Best Pract. Res. Clin. Anaesthesiol. 2014, $28,363-380$. [CrossRef] [PubMed]

36. Vasan, R.; Larson, M.; Leip, E. Impact of high-normal blood pressure on the risk of cardiovascular disease. ACC Curr. J. Rev. 2002, 11, 31. [CrossRef]

37. Romagnoli, S.; Ricci, Z.; Quattrone, D.; Tofani, L.; Tujjar, O.; Villa, G.; Romano, S.M.; De Gaudio, A.R. Accuracy of invasive arterial pressure monitoring in cardiovascular patients: An observational study. Crit. Care 2014, 18, 644. [CrossRef] [PubMed]

38. Kang, J.H.; Kim, J.K.; Hong, S.H.; Lee, C.H.; Choi, B.Y. Heart Rate Variability for Quantification of Autonomic Dysfunction in Fibromyalgia. Ann. Rehabil. Med. 2016, 40, 301. [CrossRef] [PubMed]

39. Tsao, J.; Evans, S.; Seidman, L.; Lung, K.; Zeltzer, L.; Naliboff, B. Heart rate variability as a biomarker for autonomic nervous system response differences between children with chronic pain and healthy control children. J. Pain Res. 2013, 6, 449. [CrossRef]

40. Tereshchenko, L.G.; Cygankiewicz, I.; McNitt, S.; Vazquez, R.; Bayes-Genis, A.; Han, L.; Sur, S.; Couderc, J.P.; Berger, R.D.; de Luna, A.B.; et al. Predictive Value of Beat-to-Beat QT Variability Index Across the Continuum of Left Ventricular Dysfunction: Competing Risks of Noncardiac or Cardiovascular Death and Sudden or Nonsudden Cardiac Death. Circ. Arrhythmia Electrophysiol. 2012, 5, 719-727. [CrossRef]

41. Khandoker, A.H.; Jelinek, H.F.; Palaniswami, M. Identifying diabetic patients with cardiac autonomic neuropathy by heart rate complexity analysis. BioMedical Eng. OnLine 2009, 8, 3. [CrossRef]

42. Schwerdtfeger, A.R.; Schwarz, G.; Pfurtscheller, K.; Thayer, J.F.; Jarczok, M.N.; Pfurtscheller, G. Heart rate variability (HRV): From brain death to resonance breathing at 6 breaths per minute. Clin. Neurophysiol. 2020, 131, 676-693. [CrossRef]

43. Hales, S.; Innys, W.; Manby, R.; Woodward, T. Statical Essays, Containing Haemastaticks, or, An Account of Some Hydraulick and Hydrostatical Experiments Made on the Blood and Blood Vessels of Animals: Also an Account of Some Experiments on Stones in the Kidneys and Bladder: With an Enquiry into the Nature of Those Anomalous Concretions: To Which is Added, an Appendix, Containing Observations and Experiments Relating to Several Subjects in the First Volume, the Greater Part of Which were Read at Several Meetings before the Royal Society: With an Index to Both Volumes; Innys, W., Manby, R., Woodward, T., Eds.; Printed for W. Innys and R. Manby, at the west-end of St. Paul's, and T. Woodward, at the Half-Moon between Temple-Gate, Fleetstreet: London, UK, 1733. [CrossRef]

44. Ludwig, C. Beiträge zur Kenntniss des Einflusses der Respirationsbewegungen auf den Blutlauf im Aortensysteme. Arch. Für Anat. Physiol. Und Wiss. Med. 1847, 4, 242-302.

45. Mukhopadhyay, S.C.; Pimentel, M.A.; Charlton, P.H.; Clifton, D.A. Probabilistic Estimation of Respiratory Rate from Wearable Sensors. In Wearable Electronics Sensors: For Safe and Healthy Living; Number Volume 15 in Smart Sensors, Measurement and Instrumentation; Springer: Cham, Switzerland; Heidelberg, Germany; New York, NY, USA, 2015; Chapter 10, p. 243.

46. Lehrer, P.; Carr, R.E.; Smetankine, A.; Vaschillo, E.; Peper, E.; Porges, S.; Edelberg, R.; Hamer, R.; Hochron, S. EMG and Incentive Inspirometry Biofeedback for Asthma: A Pilot Study. Appl. Psychophysiol. Biofeedback 1997, 22, 95-109. [CrossRef]

47. Citi, L.; Bianchi, M.T.; Klerman, E.B.; Barbieri, R. Instantaneous monitoring of sleep fragmentation by point process heart rate variability and respiratory dynamics. In Proceedings of the 2011 Annual International Conference of the IEEE Engineering in Medicine and Biology Society, Boston, MA, USA, 30 August-3 September 2011; pp. 7735-7738. 
48. Giardino, N.D.; Chan, L.; Borson, S. Combined Heart Rate Variability and Pulse Oximetry Biofeedback for Chronic Obstructive Pulmonary Disease: Preliminary Findings. Appl. Psychophysiol. Biofeedback 2004, 29, 121-133. [CrossRef] [PubMed]

49. CEPT/ECC. ERC Report 25: The Eropean Table of Frequency Allocations and Applications in the Frequency Range $8.3 \mathrm{kHz}$ to $3000 \mathrm{GHz}$ (ECA Table). Available online: https:/ / www.ecodocdb.dk/download/2ca5fcbd4090/ERCREP025.pdf (accessed on 20 May 2020).

50. Wang, G.; Munoz-Ferreras, J.M.; Gu, C.; Li, C.; Gomez-Garcia, R. Application of Linear-Frequency-Modulated Continuous-Wave (LFMCW) Radars for Tracking of Vital Signs. IEEE Trans. Microw. Theory Tech. 2014, 62, 1387-1399. [CrossRef]

51. GmbH, S.R. Radar Evaluation Kits for various Front Ends. Available online: https://siliconradar.com/ evalkits / (accessed on 17 April 2020).

52. Pauli, M.; Gottel, B.; Scherr, S.; Bhutani, A.; Ayhan, S.; Winkler, W.; Zwick, T. Miniaturized Millimeter-Wave Radar Sensor for High-Accuracy Applications. IEEE Trans. Microw. Theory Tech. 2017, 65, 1707-1715. [CrossRef]

53. Zwick, T.; Boes, F.; Gottel, B.; Bhutani, A.; Pauli, M. Pea-Sized mmW Transceivers: QFN-? Based Packaging Concepts for Millimeter-Wave Transceivers. IEEE Microw. Mag. 2017, 18, 79-89. [CrossRef]

54. Frischen, A.; Hasch, J.; Waldschmidt, C. A Cooperative MIMO Radar Network Using Highly Integrated FMCW Radar Sensors. IEEE Trans. Microw. Theory Tech. 2017, 65, 1355-1366. [CrossRef]

55. Wang, J.; Wang, X.; Chen, L.; Huangfu, J.; Li, C.; Ran, L. Noncontact Distance and Amplitude-Independent Vibration Measurement Based on an Extended DACM Algorithm. IEEE Trans. Instrum. Meas. 2014, 63, 145-153. [CrossRef]

56. Huang, N.E.; Shen, Z.; Long, S.R.; Wu, M.C.; Shih, H.H.; Zheng, Q.; Yen, N.C.; Tung, C.C.; Liu, H.H. The empirical mode decomposition and the Hilbert spectrum for nonlinear and non-stationary time series analysis. Proc. R. Soc. Lond. Ser. A Math. Phys. Eng. Sci. 1998, 454, 903-995. [CrossRef]

57. Geddes, L.A. Handbook of Blood Pressure Measurement; Humana Press: Clifton, NJ, USA, 1991.

58. Van Varik, B.J.; Rennenberg, R.J.M.W.; Reutelingsperger, C.P.; Kroon, A.A.; de Leeuw, P.W.; Schurgers, L.J. Mechanisms of arterial remodeling: Lessons from genetic diseases. Front. Genet. 2012, 3. [CrossRef] [PubMed]

59. Janbakhshi, P.; Shamsollahi, M.B. ECG-derived respiration estimation from single-lead ECG using gaussian process and phase space reconstruction methods. Biomed. Signal Process. Control 2018, 45, 80-90. [CrossRef]

60. Kobayashi, H. Normalization of Respiratory Sinus Arrhythmia by Factoring in Tidal Volume. Appl. Hum. Sci. J. Physiol. Anthropol. 1998, 17, 207-213. [CrossRef]

61. Jung, H.K.; Noh, Y.H.; Jeong, D.U. A Design of EMD-based Filter to Remove Motion artifacts in Wireless ECG Monitoring. J. Converg. Inf. Technol. 2013, 8, 660-668. [CrossRef]

62. Mostafanezhad, I.; Yavari, E.; Boric-Lubecke, O.; Lubecke, V.M.; Mandic, D.P. Cancellation of Unwanted Doppler Radar Sensor Motion Using Empirical Mode Decomposition. IEEE Sensors J. 2013, 13, 1897-1904. [CrossRef]

63. Dragomiretskiy, K.; Zosso, D. Variational Mode Decomposition. IEEE Trans. Signal Process. 2014, 62, 531-544. [CrossRef]

(C) 2020 by the authors. Licensee MDPI, Basel, Switzerland. This article is an open access article distributed under the terms and conditions of the Creative Commons Attribution (CC BY) license (http://creativecommons.org/licenses/by/4.0/). 